\title{
Characterization of Salinity Tolerance of Transgenic Rice Lines Harboring HsCBL8 of Wild Barley (Hordeum spontanum) Line from Qinghai-Tibet Plateau
}

\section{OPEN ACCESS}

Edited by:

Vasileios Fotopoulos, Cyprus University of Technology, Cyprus

Reviewed by:

Meixue Zhou,

University of Tasmania, Australia

Liezhao Liu,

Southwest University, China

*Correspondence:

Lixi Jiang

jianglx@zju.edu.cn

${ }^{\dagger}$ These authors have contributed equally to this work.

Specialty section:

This article was submitted to Crop Science and Horticulture, a section of the journal

Frontiers in Plant Science

Received: 12 August 2016

Accepted: 25 October 2016

Published: 10 November 2016

Citation:

Guo W, Chen T, Hussain N, Zhang G and Jiang $L$ (2016) Characterization of

Salinity Tolerance of Transgenic Rice

Lines Harboring HSCBL8 of Wild

Barley (Hordeum spontanum) Line from Qinghai-Tibet Plateau.

Front. Plant Sci. 7:1678. doi: 10.3389/fpls.2016.01678

\author{
Wanli Guo ${ }^{1,2 \dagger}$, Tianlong Chen ${ }^{1 \dagger}$, Nazim Hussain ${ }^{1}$, Guoping Zhang ${ }^{1}$ and Lixi Jiang ${ }^{1 *}$ \\ ${ }^{1}$ Institute of Crop Science, College of Agriculture and Biotechnology, Zhejiang University, Hangzhou, China, ${ }^{2}$ Department of \\ Biotechnology, College of Life Science, Zhejiang Sci-Tech University, Hangzhou, China
}

Rice is more sensitive to salinity, particularly at its early vegetative and later productive stages. Wild plants growing in harsh environments such as wild barley from Qinghai-Tibet Plateau adapt to the adverse environment with allelic variations at the loci responsible for stressful environment, which could be used for rice genetic improvement. In this study, we overexpressed HsCBL8 encoding a calcium-sensor calcineurin B-like (CBL) protein in rice. The gene was isolated from XZ166, a wild-barley (Hordeum spontanum) line originated from Qinghai-Tibet Plateau. We found that XZ166 responded to high $\mathrm{NaCl}$ concentration $(200 \mathrm{mM})$ with more HsCBL8 transcripts than CM72, a cultivated barley line known for salinity tolerance. XZ166 is significantly different from CM72 with nucleotide sequences at HSCBL8. The overexpression of HSCBL8 in rice resulted in significant improvement of water protection in vivo and plasma membrane, more proline accumulation, and a reduction of overall $\mathrm{Na}^{+}$uptake but little change in $\mathrm{K}^{+}$concentration in the plant tissues. Notably, $\mathrm{HsCBL}_{8}$ did not act on some genes downstream of the rice $\mathrm{CBL}$ family genes, suggesting an interesting interaction between $\mathrm{HsCBL8}$ and unknown factors to be further investigated.

Keywords: salt tolerance, HsCBL8, rice, Arabidopsis, Hordeum spontanum

\section{INTRODUCTION}

High salinity is one of the most prevalent abiotic stresses that pose severe reduction in plants growth and productivity of crops such as rice (Oryza sativa) grown in coastal and irrigated lands (Martínez-Atienza et al., 2007). Approximately 6\% (800 million hectares) of world's total land area has been reported as salt affected (Romeza and Flowers, 2008), mainly contributed by accumulation of salts over time in arid and semiarid regions, salts from oceans brought in by wind and rain, and weathering of the rocks (Rengasamy, 2002). Sodium chloride $(\mathrm{NaCl})$ is usually considered as the major soluble salt in saline soils encountered by plants (Munns and Tester, 2008). The responses of rice to salt stress could involve the regulation of membrane integrity, ionic compartmentation, osmotic adjustment and accumulation of macromolecules (Hu et al., 2012). To cope with deleterious effects of salt stress, efforts have been made to map QTLs that respond to salt stress in rice and barley (Gao and Lin, 2013; Long et al., 2013; Ahmadi-Ochtapeh et al., 2015; Das and Rao, 2015), clone genes based on mapping and transfer elite genes from wild barley into rice (Ellis et al., 2000). 
Wild barley (H. spontanum), native to Qinghai-Tibet Plateau, has more genetic diversity compared with other wild and cultivated barley species, and the plateau is also considered as the center of the origin for cultivated barley in the oriental region (Dai et al., 2012). Wild barley species thrive best to survive under harsh environments, such as drought (Ahmed et al., 2013) and salt stress (Wu et al., 2013), and could provide elite gene pool for crop improvement (Ellis et al., 2000). Some genes from cultivated barley response to stresses, for example, $\mathrm{HvCBL} 4$ (calcium-sensor calcineurin B-like, CBL), a close homolog of the $A t C B L 4$, positively responded to salinity in Arabidopsis (Rivandi et al., 2011). Moreover, the overexpression of $\mathrm{HvCBF} 4$ (C-repeat/dehydration-responsive element binding factors, $\mathrm{CBF} / \mathrm{DREBs}$ ) in transgenic rice plants induced tolerance against drought, salinity and low-temperature stresses with normal plant growth (Oh et al., 2007). Maintaining low level of $\mathrm{Na}^{+}$and narrow $\mathrm{Na}^{+} / \mathrm{K}^{+}$ratio in the cytosol is critical for cellular metabolism and salt tolerance in glycophytes (Qiu et al., 2002). One such example is of tolerant rice subspecies that can exclude $\mathrm{Na}^{+}$from the shoot and maintain a low $\mathrm{Na}^{+} / \mathrm{K}^{+}$ratio (Mekawy et al., 2015). To date, only HbCIPK2 from a wild barley species (H. brevisubulatum) was reported as a positive regulator of salt and osmotic stress responses, and as a factor to control $\mathrm{Na}^{+} / \mathrm{K}^{+}$homeostasis in Arabidopsis (Li et al., 2012). However, little is known about the functional attributes of the gene(s) in response to abiotic stresses in $H$. spontanum from Qinghai-Tibet Plateau.

Calcium ion $\left(\mathrm{Ca}^{2+}\right)$, the most dynamic second messenger in all eukaryotic organisms, interacts with many binding proteins such as calmodulin (CaM), calmodulin like proteins (CAML), and CBLs. Among these proteins, CBLs, which are small $\mathrm{Ca}^{2+}$ binding proteins, mainly interact with $\mathrm{CBL}$-interacting protein kinase (CIPK) as an upstream factor for downstream signaling and in response to several abiotic factors, including salt, cold, drought, proton, reactive oxygen species (ROS), abscisic acid (ABA) and gibberellins (GA) (Thoday-Kennedy et al., 2015). CBLs are most similar to the regulatory $B$ subunit of calcineurin (CNB), a protein phosphatase in animals (Liu and Zhu, 1998). Therefore, the $\mathrm{Ca}^{2+}$ binding capacity of the CBL protein is dependent on the number and structure of the elongation factorhand domain (EF-hand), that could affect the stability of CBLCIPK complex (Weinl and Kudla, 2009).

The first CBL protein that reacts to salt stress is AtCBL4 (Liu and Zhu, 1998). The active complex of CBL4-CIPK24 complex is activated downstream the $\mathrm{Na}^{+} / \mathrm{H}^{+}$antiporter (NHX) to induce $\mathrm{Na}^{+}$efflux from roots under high salt conditons (Qiu et al., 2002). The interaction between AtCBL10 and CIPK24 under salt stress also activates the $\mathrm{Na}^{+}$transporter to transfer $\mathrm{Na}^{+}$ to the vacuole of shoots or leaves (Quan et al., 2007). AtCBL1, $A t C B L 5$, and $A t C B L 9$ are also involved in the response signaling to salt, drought, osmotic and ROS stress (Thoday-Kennedy et al., 2015). AtCBL2 and AtCBL3 could regulate the activity of proton pump V-ATPase on the vacuole membrane to maintain the ion homeostasis in the cell. By contrast, double-cbl2/cbl3mutant plants were found more resistant to high $\mathrm{Na}^{+}$and low $\mathrm{K}^{+}$conditions (Tang et al., 2012). Similar stress responses of CBLs have also been reported in rice OsCBL8 (Xiang et al.,
2007), Ammopiptanthus mongolicus AmCBL1 (Chen et al., 2011), soybean $G m C B L 1$ (Li et al., 2012), rape BnCBL1 (Chen et al., 2012), and tobacco NsylCBL10 (Dong et al., 2015). Ten CBL proteins have also been discovered in Arabidopsis, rice and populous (Albrecht et al., 2001; Kolukisaoglu et al., 2004; Zhang et al., 2008). Eight CBLs have also been detected in maize, sorghum and grape (Weinl and Kudla, 2009). Seven CBLs have been found in canola (Zhang et al., 2014).

HsCBL8 exhibits a significantly distant phylogenetic relationship between with salt-responsive AtCBL4; this relationship indicates that $H s C B L 8$ can differ from other known plant CBLs (Liu and Zhu, 1998). This finding also shows that $H s C B L 8$ may function in a mechanism different from that of AtCBL4. Some CBL proteins, such as AtCBL1, AtCBL4, AtCBL5, AtCBL8, and AtCBL9 modified through N-myristoylation or S-acylation (Batistic et al., 2012), can acquire functional characteristics in membrane-localized dependent signaling in plant cells. By contrast, CBLs, including AtCBL2, AtCBL3, AtCBL6, and AtCBL7, are characterized by N-myristoylation motifs (MGCXXS/T). In this study, $H s C B L 8$ was cloned from a wild barely ( $H$. spontanum) line XZ166 native to Qinghai-Tibet Plateau and highly tolerant to severe salt stress. This study aimed to investigate the growth performance of transgenic rice plants expressing $H s C B L 8$ in response to salt stress and to explore the related mechanism.

\section{MATERIALS AND METHODS}

\section{Plant Materials and Their Growth Conditions}

The seeds of the Qinghai-Tibetan annual wild barley line XZ166 (H. spontanum) and cultivated barley CM72 (H. vulgare L. ssp. Vulgare), Arabidopsis thaliana ecotype Columbia-0 (Col-0), and rice Zhonghua11 (ZH11, Oryza sativa) were obtained from the Provincial Key Laboratory of Gene Resources, Zhejiang University, Hangzhou, China. The seeds of XZ166 and CM72 were surface sterilized in $5 \% \mathrm{NaClO}$ for $15 \mathrm{~min}$, rinsed with tap water, and germinated on moistened fine sand in plastic pots $(15 \mathrm{~cm} \times 20 \mathrm{~cm} \times 15 \mathrm{~cm})$ for 2 days at $25^{\circ} \mathrm{C}$ in the dark. The plastic pots with germinated seeds were then transferred to a greenhouse under a $14 \mathrm{~h}$ light $\left(420 \mu \mathrm{mol} \mathrm{m} \mathrm{m}^{-2} \mathrm{~s}^{-1}\right)$ period at $25^{\circ} \mathrm{C}$ and $10 \mathrm{~h}$ dark period at $23^{\circ} \mathrm{C}$ daily. We adopted $70 \%$ relative humidity and watered the plants with nutrient solution ( $\mathrm{pH}$ 6.0, mg L ${ }^{-1}$ ) that contained $\left(\mathrm{NH}_{4}\right)_{2} \mathrm{SO}_{4}$ (48.2), $\mathrm{MgSO}_{4}$ (154.88), $\mathrm{K}_{2} \mathrm{SO}_{4}$ (15.9), $\mathrm{KNO}_{3}$ (18.5), $\mathrm{KH}_{2} \mathrm{PO}_{4}(24.8), \mathrm{Ca}\left(\mathrm{NO}_{3}\right)_{2}$ (86.17), Fe-citrate (7), $\mathrm{MnCl}_{2} \cdot 4 \mathrm{H}_{2} \mathrm{O}(0.9), \mathrm{ZnSO}_{4} \cdot 7 \mathrm{H}_{2} \mathrm{O}(0.11)$, $\mathrm{CuSO}_{4} \cdot 5 \mathrm{H}_{2} \mathrm{O}(0.04), \mathrm{HBO}_{3}$ (2.9), and $\mathrm{H}_{2} \mathrm{MoO}_{4}$ (0.01). The solution was renewed at 6-day intervals, and its value was adjusted to $\mathrm{pH} 6.0 \pm 0.1$ using $1 \mathrm{M} \mathrm{HCl}$ daily. $\mathrm{CaCl}_{2}$ was added with $\mathrm{NaCl}$ to maintain a molar ratio of $\mathrm{Na}^{+}: \mathrm{Ca}^{2+}=10: 1$.

The Arabidopsis ecotype Col-0 and the $\mathrm{T}_{2}$ plants

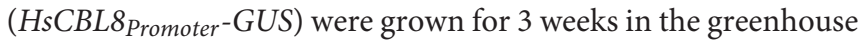
(16 h light, $110 \mu \mathrm{mol} \mathrm{m}^{-2} \mathrm{~s}^{-1}$ ), subsequently transferred to half strength MS liquid media, and allowed to grow for 1 week on the medium. After the plants became adapted to the MS media, different treatments, including $100 \mu \mathrm{M} \mathrm{ABA}, 100 \mathrm{mM} \mathrm{NaCl}$, and 
20\% PEG6000 with 5\% sucrose were applied at $4^{\circ} \mathrm{C}$ for $12 \mathrm{~h}$. Moreover, plants in different developmental stages were used for $\beta$-glucuronidase GUS histochemical staining.

The seed dormancy of $\mathrm{ZH} 11$ and transgenic plants (35S-HsCBL8) was terminated with treatment of $0.5 \% \mathrm{H}_{2} \mathrm{O}_{2}$ for $12 \mathrm{~h}$. The seeds were then sterilized in $5 \% \mathrm{NaClO}$ for $20 \mathrm{~min}$, rinsed with tap water, and germinated on moistened filter papers in an incubator in a $14 \mathrm{~h}$ light period $\left(110 \mu \mathrm{mol} \mathrm{m} \mathrm{m}^{-2} \mathrm{~s}^{-1}\right)$ and $10 \mathrm{~h}$ dark period at $25^{\circ} \mathrm{C}$. To calculate the germination rate, 20 rice seeds per biological repeat (four repeats independently) were treated with $125 \mathrm{mM} \mathrm{NaCl}$ in $1 / 4$ nutrient solution. Moreover, the solution was renewed daily. Data on germination were collected from the "specific day" until 70 to $80 \%$ was reached per treatment for each genotype. Then the germination rate was calculated.

\section{Molecular Cloning of HsCBL8}

Seedlings of the XZ166 with three leaves were treated with $200 \mathrm{mM} \mathrm{NaCl}$ for $48 \mathrm{~h}$, and their roots were selected for RNA extraction. Total RNA was extracted by a kit method (OMEGA, Norcross, GA RNA kit). PrimeScript ${ }^{\text {TM }}$ First Strand cDNA Synthesis Kit (Takara, Dalian China) was used to synthesize the cDNA. The genomic DNA of the XZ166 leaves was extracted using the CTAB method. The degenerate primers (Table S1) were designed based on cDNA sequences available on the National Center for Biotechnology Information (NCBI) database with accession IDs AL713904, FJ901265.1, EU085040.1, AB378095.1, XM_002524988.1, DQ907707.1, DQ201200.1, FJ901264.1, and FJ901259.1. The $25 \mu \mathrm{L}$ PCR reaction mix used for amplification included L-Taq polymerase (Takara, Dalian China) (1.5 units), genomic DNA (25 ng), per primer $10 \mu \mathrm{M}$, dNTP (20 mM). PCR amplification was performed as follows: $95^{\circ} \mathrm{C}$ for $3 \mathrm{~min}, 10$ cycles of $94^{\circ} \mathrm{C}$ for $30 \mathrm{~s}$, and $60^{\circ} \mathrm{C}$ for $30 \mathrm{~s}$ at $-0.5^{\circ} \mathrm{C}$ per cycle; $72^{\circ} \mathrm{C}$ for $60 \mathrm{~s}$; and 25 cycles of $94^{\circ} \mathrm{C}$ for $30 \mathrm{~s}, 55^{\circ} \mathrm{C}$ for $30 \mathrm{~s}, 72^{\circ} \mathrm{C}$ for $60 \mathrm{~s}$, and $72^{\circ} \mathrm{C}$ for $5 \mathrm{~min}$. The PCR products were separated by $1.0 \%$ agarose gel electrophoresis. We obtained four wild barley CBL sequence candidates; one of which was identified as cultivated barley EST FLbaf27i23 under the Barley Database (http://www.shigen.nig.ac.jp/barley/). The coding sequences (CDSs) of its cDNA and genomic DNA were amplified using primers designed from FLbaf27i23, which contained additional $X b a$ I and $B a m H$ I restriction sites (underlined, Table S1), respectively. The $H s C B L 8$ promoter was cloned using inverse PCR (IPCR, http://dps.plants.ox.ac.uk/langdalelab/protocols) combined with nested PCR. Genomic DNA (2.5 $\mu \mathrm{g})$ was cut by Xho I and Cla I independently; the DNAs ligated by T4 DNA ligase (Takara, Daliang China) were employed for amplification. The primers used are shown in Table S1. The prepared $25 \mu \mathrm{L}$ PCR reaction mix included LTaq polymerase (Takara, Dalian China) (1.5 units), genomic DNA (50 ng), per primer $(10 \mu \mathrm{M})$, and dNTPs $(20 \mathrm{mM})$. PCR amplification was performed as follows: $95^{\circ} \mathrm{C}$ for $3 \mathrm{~min}, 10$ cycles of $94^{\circ} \mathrm{C}$ for $30 \mathrm{~s}, 60^{\circ} \mathrm{C}$ for $30 \mathrm{~s},-0.5^{\circ} \mathrm{C}$ per cycle, and $72^{\circ} \mathrm{C}$ for $3 \mathrm{~min}$; 25 cycles of $94^{\circ} \mathrm{C}$ for $30 \mathrm{~s}, 55^{\circ} \mathrm{C}$ for $30 \mathrm{~s}, 72^{\circ} \mathrm{C}$ for $3 \mathrm{~min}$; and $72^{\circ} \mathrm{C}$ for $5 \mathrm{~min}$. PCR products were separated by $1.0 \%$ agarose gel electrophoresis. Then, the $H s C B L 8$ promoter region was amplified using primers (Table S1) that contained additional Hind III and Xba I restriction sites (underlined).

\section{Analysis of HsCBL8 CDS and Promoter Sequences}

Nucleotide and protein sequences (Table S2) were analyzed by BioEdit 7.2.5 software (Abbott, Carlsbad, Canada) and NCBI (http://blast.ncbi.nlm.nih.gov/). Amino acid sequence alignment was analyzed by Clustal $\mathrm{X}$, and phylogenetic trees were established by the neighborhood-joining bootstrap method; using the default parameters in the software MEGA 6.06 (http://www.megasoftware.net/index.php). The cis elements of the $H s C B L 8$ promoter sequence (the upstream 1000 bp from the initiation codon) were predicted by PlantCARE online (http://bioinformatics.psb.ugent.be/webtools/plantcare/html/).

\section{Vector Construct and Plant Transformation}

The transgenic Arabidopsis plants harboring

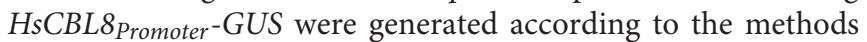
we previously described (Wang et al., 2014). In brief, a 2160 bp HsCBL8 promoter and GUS was inserted into pCAMBIA1300 binary vector. After verification by restrictive digestion and DNA sequencing, the construct was applied to transform wild type plants by floral dipping using Agrobacteria tumefaciens strain GV3103. Transgenic plants $\left(\mathrm{T}_{0}\right)$ survived on solid Murashige and Skoog (MS) medium containing $30 \mathrm{mg} \mathrm{ml}^{-1}$ hygromycin were further verified by PCR genotyping. T1 and T2 seedlings were selected by PCR genotyping with the primers listed in Table S1.

pCAMBIA1300 was modified by inserting the CaMV $35 S$ promoter-GUS (35S-GUS) region cut from pBI121 using Hind III and EcoR I and named as pCAMBIA1300-35S-GUS. The genomic DNA of the $H s C B L 8$ coding region was inserted into the Xba I and BamH I sites of the pCAMBIA1300-35S-GUS plasmid to form expression vector $p C A M B I A 1300-35 S-H s C B L 8$ (Figure 1A). This construct was transferred into Agrobacterium tumefaciens EHA105 and used for rice ZH11 transformation. Callus induction and subculture were performed on the medium supplemented with $2 \mathrm{mg} / \mathrm{L}$ 2,4-D, 3\% sucrose, and 0.55\% agar, named NB medium by Ozawa (2012). After a number of subcultures with an interval of 4 weeks, calli (between 1 and $3 \mathrm{~mm}$ in diameter) were used for transformation by co-culture with EHA105 harboring pCAMBIA1300-35S-HsCBL8. Then, the cocultured calli were transferred onto pre-selection medium (NB supplemented with $30 \mathrm{mg} / \mathrm{L}$ hygromycin B), and incubated in the dark for 7 days. Subsequently, the differentiated calli were placed on the selection medium (NB with $50 \mathrm{mg} / \mathrm{L}$ hygromycin $\mathrm{B}$ ) for another 14-17 days. The resistant calli were then transferred to pre-regeneration medium (NB supplemented with $2 \mathrm{mg} / \mathrm{L}$ 6-BA, $1 \mathrm{mg} / \mathrm{L} \mathrm{NAA}, 5 \mathrm{mg} / \mathrm{L} \mathrm{ABA}$ and $50 \mathrm{mg} / \mathrm{L}$ hygromycin B) and cultured in the dark for 7 days, followed by plant regeneration on medium $\mathrm{NB}$ supplemented with $3 \mathrm{mg} / \mathrm{L}$ 6-BA, $0.5 \mathrm{mg} / \mathrm{L} \mathrm{NAA}$ and $50 \mathrm{mg} / \mathrm{L}$ hygromycin $\mathrm{B}$, for 14-21 days under a $16 \mathrm{~h}$ photoperiod until shoots appeared. Regenerated plants were subsequently transferred into greenhouse and selfpollinated to produce progenies.. The transgenic rice was first selected by hygromycin and PCR analysis using primers listed in Table S1, and then confirmed by Southern blot. The $35 \mathrm{~S}$ region of the $P C A M B I A 1300-35 S-G U S$ plasmid was replaced by the $H s C B L 8$ promoter (2170 bp before the initiation codon; 

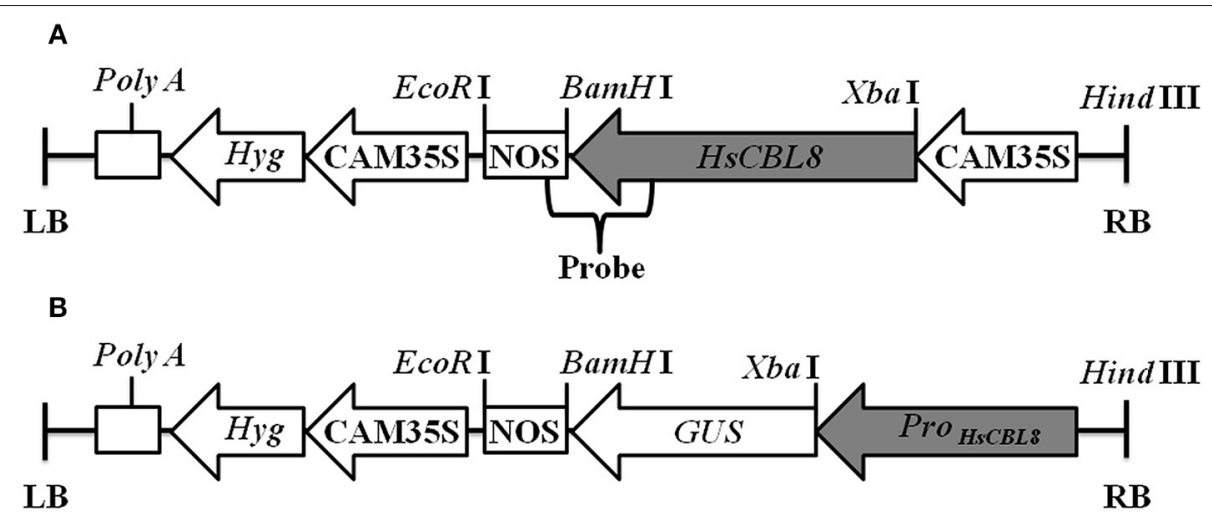

FIGURE 1 | Linear maps of the molecular constructs 35S-HsCBL8 (A) and HsCBL8promoter-GUS (B) in the pCAMBIA1300 vector used for transformation. LB, left border; RB, right border; Hyg, Hygromycin B phosphotransferase gene; CAM35S, Cauliflower mosaic virus 35S promoter; NOS, Nos terminator; GUS, $\beta$-Glucuronidase gene; ProHsCBL8, HsCBL8 promoter.

$\left.H s C B L 8_{\text {promoter }}\right)$ to form the vector $p C A M B I A 1300-$ ProHsCBL8GUS using Hind III and Xba I (Figure 1B). This construct was transferred into A. tumefaciens GV3101 and used for Arabidopsis (Col-0) transformation by the floral dip method with slight modification. The Arabidopsis plants were grown in a greenhouse for about 4 weeks with a cycle of $16 \mathrm{~h}$ light and $8 \mathrm{~h}$ dark periods before transformation. GV3101 cells, cultured in LuriaBertani (LB) medium for $18-20 \mathrm{~h}$ at $28^{\circ} \mathrm{C}$ (optical density at $\left.600 \mathrm{~nm}\left[\mathrm{OD}_{600}\right]: 1.6-2.0\right)$, were collected by centrifugation and re-suspended in infiltration medium (half-strength MS medium, $5 \%$ sucrose, $0.044 \mu \mathrm{M}$ benzylamino purine, and $0.2 \%$ Silwet L-77) to an $\mathrm{OD}_{600}$ of $0.8-1.0$. Plant inflorescences were dipped in the infiltration solution for $2 \mathrm{~min}$, and transferred to a dark chamber in a greenhouse for 2 days, and then cultured under normal conditions. Transgenic plants $\left(\mathrm{T}_{0}\right)$ survived on solid Murashige and Skoog (MS) medium containing $30 \mathrm{mg} \mathrm{ml}^{-1}$ hygromycin, were further verified by PCR genotyping. T1 and T2 seedlings were selected by PCR genotyping with the primers listed in Table S1.

\section{PCR Analysis}

Both genomic and cDNA were identified. The specific primers (Table S1) from $H s C B L 8$ genomic DNA were used to separately amplify $679 \mathrm{bp}$ fragments. The specific primers (Table S1) from the $H s C B L 8$ cDNA were used to amplify 596 bp fragments, and $O s G A P D H$ was used as reference gene $(425 \mathrm{bp})$. The prepared $20 \mu \mathrm{L}$ PCR reaction mix contained rTaq polymerase (Takara, Dalian China) (1.0 units), genomic DNA (20 ng), per primer $(10 \mu \mathrm{M})$, and dNTP $(10 \mathrm{mM})$. The following PCR program was used: $95^{\circ} \mathrm{C}$ for $4 \mathrm{~min} ; 25$ cycles of $94^{\circ} \mathrm{C}$ for $30 \mathrm{~s}, 58^{\circ} \mathrm{C}$ for $30 \mathrm{~s}$, and $72^{\circ} \mathrm{C}$ for $60 \mathrm{~s}$; and $72^{\circ} \mathrm{C}$ for $5 \mathrm{~min}$. The PCR products were separated by $1.0 \%$ agarose gel electrophoresis.

\section{Southern Blot Analysis}

Approximately $10 \mu \mathrm{g}$ DNA per sample was separately and completely digested by Hind III and EcoR I, separately, and the restriction fragments were separated with $0.8 \%(\mathrm{w} / \mathrm{v})$ agarose gel. Then, DNA was transferred onto a Hybond $\mathrm{N}^{+}$nylon membrane (Boehringer, Mannheim, Germany) for $12 \mathrm{~h}$, and the membrane was hybridized using a specific probe, including HsCBL8 and an NOS sequence (Figure 1A). The probe (679 bp) was then amplified in accordance with primers (Table S1) using plasmid $p C A M B I A 1300-35 S-H s C B L 8$. The probe was labeled with the enzyme horseradish peroxidase (Roche DIG High Prime DNA Labeling and Detection Starter kit II) for 10$12 \mathrm{~h}$ at $65^{\circ} \mathrm{C}$. After hybridization, the membrane was washed twice with $2 \times$ standard saline citrate (SSC) plus $0.1 \%$ sodium dodecyl sulfate (SDS) at $65^{\circ} \mathrm{C}$ for $10 \mathrm{~min}$ and washed twice with $0.5 \times$ SSC plus $0.1 \%$ SDS for $10 \mathrm{~min}$ at room temperature. The membrane was covered with the detection reagent mixture for $30 \mathrm{~min}$ in accordance with the supplier's instructions. Finally, the membrane was wrapped in Saran wrap with $1 \mathrm{ml}$ CSPD readyto-use for 5 min and subsequently detected by a Fuji Photo Film Releases LAS-3000 Imaging System (Tokyo, Japan).

\section{GUS Analysis}

Histochemical staining of GUS activity was performed as follows. Plant tissues were incubated at $37^{\circ} \mathrm{C}$ overnight in GUS staining buffer ( $2 \mathrm{mM} 5$-bromo-4-chloro-3-indolyl- $\beta$-glucuronic acid in $50 \mathrm{mM}$ sodium $\mathrm{Pi}$ buffer, $\mathrm{pH}$ 7.2) containing $0.1 \%$ Triton $\mathrm{X}-100$, $2 \mathrm{mM} \mathrm{K}_{4} \mathrm{Fe}(\mathrm{CN})_{6}, 2 \mathrm{mM} \mathrm{K}{ }_{3} \mathrm{Fe}(\mathrm{CN})_{6}$, and $10 \mathrm{mM}$ EDTA. The stained seedlings were sequentially transferred to 50, 70, and $100 \%(\mathrm{v} / \mathrm{v})$ ethanol to remove chlorophyll. The stained materials were examined with a dissecting microscope (Leica MZ95) with a digital camera. GUS activity was also determined by fluorometric assay (Gallagher, 1992).

\section{Transgenic Rice Treated with High $\mathrm{NaCl}$}

The young rice seedlings (30 days) were treated with 125 $\mathrm{mM} \mathrm{NaCl}$ in half-strength nutrient solution. Fresh weights were calculated at $0,8,16$, and $24 \mathrm{~h}$; plant phenotypes were photographed at 2, 4, and 6 days, and all leaves at 0,24 , and $72 \mathrm{~h}$ were used for analysis of proline, malondialdehyde (MDA), and $\mathrm{Na}^{+}$and $\mathrm{K}^{+}$contents, and rate of electrolyte leakage (REL). Plants without $\mathrm{NaCl}$ treatment were used as control. Meanwhile, proline content was determined as follows: $0.2 \mathrm{~g}$ fresh 
leaves were chopped and immersed in $5 \mathrm{ml}$ of $3 \%$ sulphosalicylic acid at $100^{\circ} \mathrm{C}$ to extrac free proline. Proline content was then measured by UV Spectrophotometer (UV1000, LabTech) at $520 \mathrm{~nm}$. MDA content was determined by the thiobarbituric acid (TBA) reaction. Leaves $(0.2 \mathrm{~g})$ were homogenized with 10 $\mathrm{ml}$ of $10 \%$ trichloroacetic acid (TCA) and centrifuged at 4000 $\mathrm{rpm}$ for $10 \mathrm{~min}$. Part of the supernatant $(2 \mathrm{ml})$ was mixed with $2 \mathrm{ml} 0.6 \% \mathrm{TBA}$ and incubated in $100^{\circ} \mathrm{C}$ water for $15 \mathrm{~min}$, then cooled immediately on ice and centrifuged at $4000 \mathrm{rpm}$ for $10 \mathrm{~min}$. $\mathrm{OD}_{450}, \mathrm{OD}_{532}$, and $\mathrm{OD}_{600}$ were determined by UV spectrophotometry (UV1000, LabTech). MDA concentration (MDAC) were calculated through the formula; MDAC ( $\mu \mathrm{mol} / \mathrm{L})$ $=\left[6.45\left(\mathrm{OD}_{532}-\mathrm{OD}_{600}\right)-0.56 \mathrm{OD}_{450}\right] \times \mathrm{V} \times \mathrm{m}$, where $\mathrm{V}$ is the volume of the total extraction liquid and $\mathrm{m}$ is the sample weight. The leaves and roots were collected and dehydrated in a Muffle furnace at $500^{\circ} \mathrm{C}$ for $6 \mathrm{~h}$. These ash samples were then extracted in $50 \% \mathrm{HNO}_{3}$ overnight. The $\mathrm{Na}^{+}$and $\mathrm{K}^{+}$contents were measured by atomic absorption spectrophotometry (Z-5000 Polarized Zeeman, Hitachi, Japan). Membrane permeability can be reflected by the REL. Fresh leaves were collected and washed three times with deionized water to remove surface-adhered electrolytes. Each sample was divided equally and placed into two sealed vials containing $10 \mathrm{ml}$ of deionized water. One vial was incubated at $25^{\circ} \mathrm{C}$ on a rotary shaker for $3 \mathrm{~h}$, and then the electrical conductivity (EC1) was measured with a conductivity meter (162A, Thermo Orion, USA). Another vial was autoclaved at $100^{\circ} \mathrm{C}$ for $20 \mathrm{~min}$, and the electrical conductivity (EC2) was determined by a conductivity meter. The REL can then be defined as $\mathrm{REL}=(\mathrm{EC} 1 / \mathrm{EC} 2)$.

In these analyses, four biological replicates were performed independently, and four plants were used in per replicate.

\section{Real-Time PCR Analysis}

XZ166 and CM72 plants (with three leaves, about 10 days) were treated with $200 \mathrm{mM} \mathrm{NaCl}$, and the roots and shoots of three plants were separately collected at $0,1,6,12,24$, and $48 \mathrm{~h}$. Similarly, ZH11 and transgenic (35S-HsCBL8) seedlings (30 days) were treated with $125 \mathrm{mM} \mathrm{NaCl}$, and shoot of three plants were separately collected at 0,3 , and $6 \mathrm{~h}$. Three biological replicates were carried out independently. The primers adopted are listed in Table S1. HvGapdh and actin mRNAs were separately employed as internal controls for barley and rice. Real-time PCR was

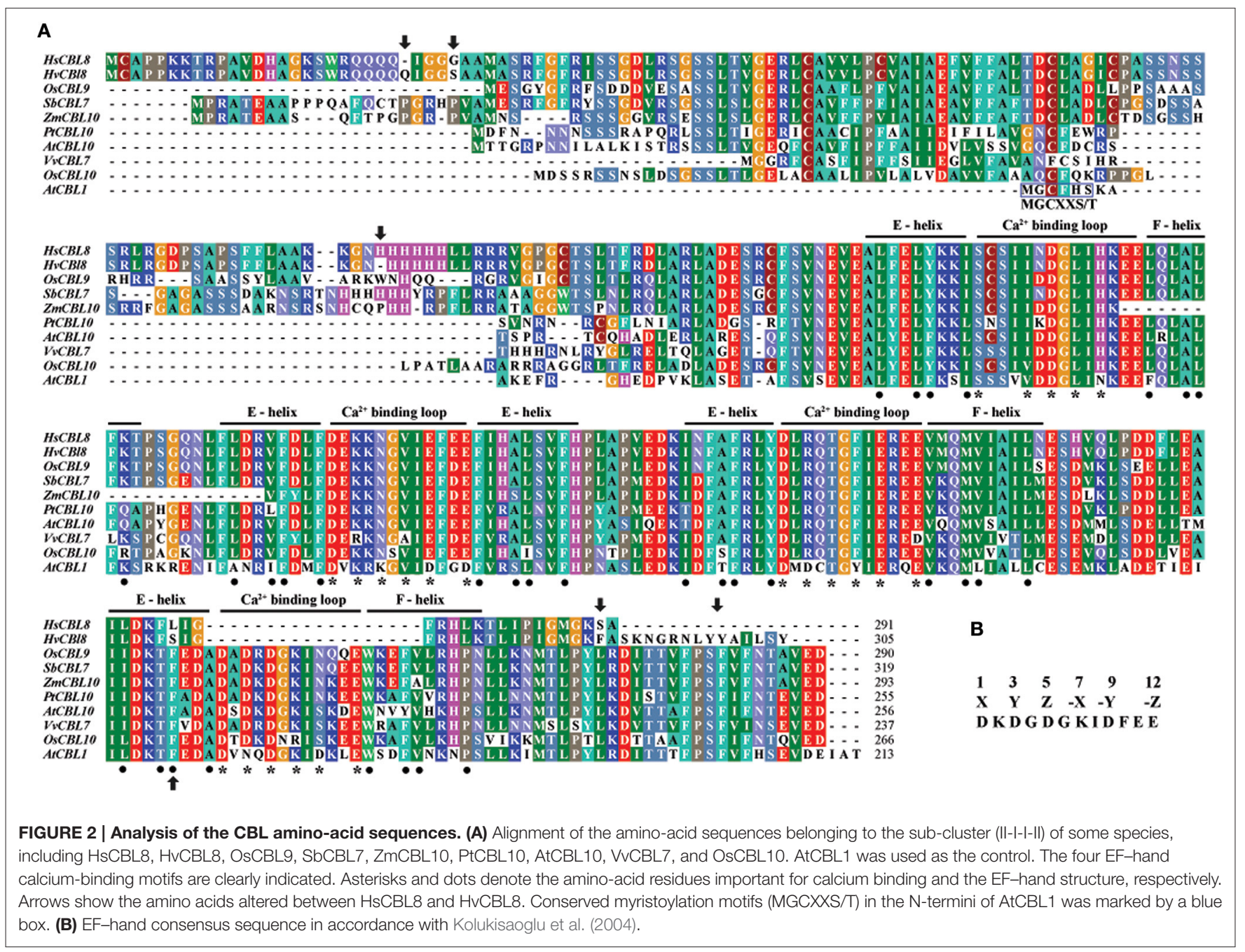


performed using the CFX96 ${ }^{\mathrm{TM}}$ system (Bio-Rad, America) with $\mathrm{iTaq}^{\mathrm{TM}}$ Universal SYBR ${ }^{\circledR}$ Green Supermix (Bio-Rad). The PCR program was implemented as follows: $95^{\circ} \mathrm{C}$ for $3 \mathrm{~min}$ and 40 cycles of $95^{\circ} \mathrm{C}$ for $15 \mathrm{~s}, 58^{\circ} \mathrm{C}$ for $15 \mathrm{~s}$, and $72^{\circ} \mathrm{C}$ for $15 \mathrm{~s}$.

\section{Statistical Analysis}

Statistical analysis for real-time PCR was conducted using the software CFX Manager (version 2.1), and the relative expression level of per gene was calculated by the $2^{-\Delta \Delta \mathrm{CT}}$ method (Livak and Schmittgen, 2001). Moreover, student's $t$-test was applied for each parameter studied. Differences were considered significant at $P<0.05$ and highly significant at $P<0.01$.

\section{RESULTS}

\section{Cloning of $\mathrm{HsCBL8}$}

The first 494 bp cDNA sequence amplified with degenerate PCR primers (Table S1) was found similar to the full-length cDNA sequence of the gene FLbaf27i23 in barley $(H$. vulgare subsp. vulgare) (http://www.shigen.nig.ac.jp/barley/). BLASTX (http://blast.ncbi.nlm.nih.gov/Blast.cgi) analysis of the coding sequence (CDS) predicted 915 nucleotides, which code HvCBL8 with 305 amino acids (Figure 2A). A fragment of 873 bp at the CDS was cloned from wild barley XZ166 using primers based on FLbaf27i23, which encodes the HsCBL8 protein of 291 amino acids (Figure 2A, NCBI, AEM44693.1). We performed IPCR of the 2388 bp fragment (NCBI ID, HQ696007.1) upstream the initial codon. Moreover, 31 cis elements of the upstream 1000 bp from initiation codon were predicted by PlantCARE. Ten of these elements were light response elements, five were MeJA response elements, four were ABA response elements, four were endosperm expression elements, three were drought response elements, two were GA-responsive and circadian control elements, and one was a salicylic acid (SA) response element (Table 1). The predicted cis elements of the HsCBL8 promoter sequence indicated that $H s C B L 8$ could be induced by different stresses (Table 1).

\section{Phylogenetic Analysis of $\mathrm{HsCBL8}$}

To study the phylogenetic relationship of $H s C B L 8$, the amino acid sequence of HsCBL8 was compared with $71 \mathrm{CBL}$ genes from plant species including monocot (rice, sorghum, maize and barley), dicot (Arabidopsis, grape and populous), and protozoan (Naegleria fowleri). The corresponding IDs are presented in Table S2. Accordingly, members of the family CBL family could be clustered into two groups (Figure 3). Group I only comprised four members. Three belonged to simple plants and N. fowleri, and one represented Arabidopsis (AtCBL5). By contrast, Group II was divided into two sub-clusters: II-I and II-II. Moreover, II-I was grouped into II-I-I and II-I-II, whereas II-I-I was subclustered into II-I-I-I and II-I-I-II. HsCBL8 was found closely related to rice OsCBL9 $(63.70 \%)$ and thus placed in the group II-I-I-II, which included 12 CBLs (Figure 3). Results revealed that most of CBLs belonging to monocots were slightly deviant phylogenetically from dicot species, whereas the CBLs of lower plants were found in close relation to higher plant species in each group (Figure 3). Moreover, HsCBL8 was significantly different to HvCBL8 in terms of a 14-amino-acids deletion at its nitrite end, and five other changed sites, including three changed, one deletion, and one more amino acid (Figure 2A). Normally, the CBL protein contains four EF-hand domains for $\mathrm{Ca}^{2+}$ ion binding (Figure 2B), but the last domain was lost in HsCBL8 and HvCBL8 (Figure 2A). Obviously, a conserved myristoylation motif $(\mathrm{MGCXXS/T})$ in the N-terminus of AtCBL1 was not discovered in the group II-I-I-II (Figure 2), including HsCBL8 (Figure 2A).

\section{Expression Analysis of $\mathrm{HsCBL8}$ in Barley under Salt Stress}

To evaluate whether $H s C B L 8$ in XZ166 and $H v C B L 8$ in CM72 could respond to salt, we conducted real time reversetranscription PCR analysis to test their expression patterns in the control and under salt stress. Results revealed that the expression of both the genes in their respective plant species, were significantly induced in their shoots and roots,

TABLE 1 | Prediction of cis-elements responding to environment stimuli in HsCBL8 promoter (the upstream 1000 bp from the initiation codon) using software PlantCARE.

\begin{tabular}{|c|c|c|c|c|}
\hline Cis-element name & DNA sequence $\left(5^{\prime}-3^{\prime}\right)$ & & -elements & Function \\
\hline ABRE & CACGTG/CCTACGTGGC/CCGCGTAGGC/TACGTG & \multicolumn{2}{|c|}{4} & Abscisic acid responsiveness \\
\hline ACE & ACGTGGA & 1 & 10 & Light responsive element \\
\hline Box 4 & АТTAAT & 1 & & \\
\hline G-box & CACGTG/CACGTA/CACATGG/CACGTC/TACGTG & 5 & & \\
\hline GATA & GATAGGG & 1 & & \\
\hline CGTCA/TGACG & CGTCA/TGACG & & & MeJA-responsiveness \\
\hline GARE & AAACAGA & & & Gibberellin-responsive element \\
\hline MBS & TAACTG/CAACTG/TAACTG & & & Drought-inducibility \\
\hline Skn-1 & GTCAT & & & Endosperm expression \\
\hline TCA & GAGAAGAATA & & & Salicylic acid responsiveness \\
\hline
\end{tabular}




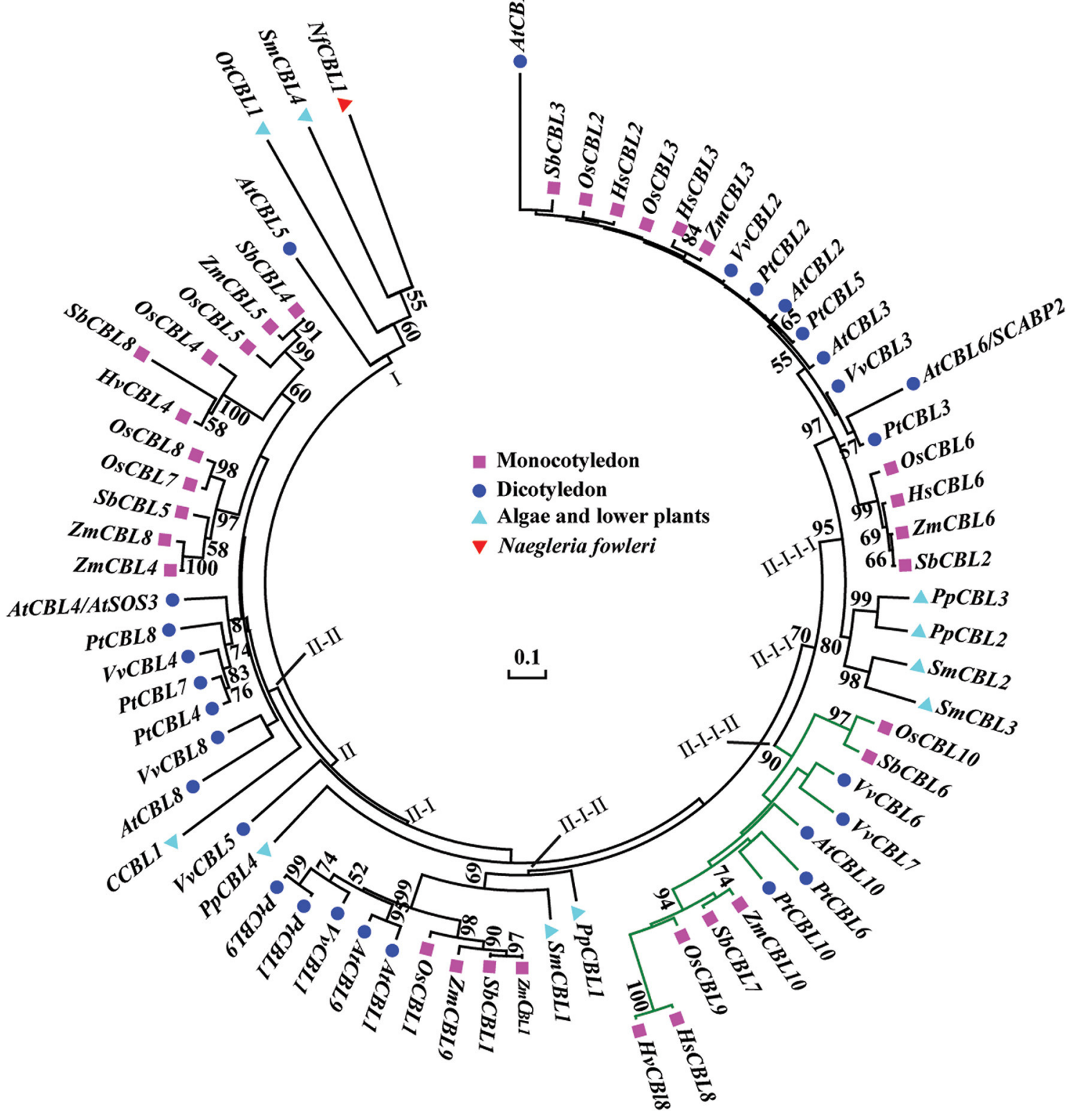

FIGURE 3 | Phylogenetic relationships of CBL proteins from algae, lower plants, higher plants, and protozoan Naegleria fowleri (Nf). The NCBI accession numbers of the $\mathrm{CBL}$ proteins in this paper are presented in Table S2. The bar shows the evolutionary distance, and the number at the nodes represents the reliability percentage (\%; only $>50 \%$ is shown) of the bootstrap values based on 1000 replications. Codification: Hs, Hordeum spontaneum; Hv, $\mathrm{H}$. vulbare; Os, Oryza sativa; Zm, Zea mays; Sb, Sorghum bicolor; At, Arabidopsis thaliana; Pt, Populus trichocarpa; Vv, Vitis vinifera; Ot, Ostreococcus tauri; C, Chlorella sp.; $\mathrm{Pp}$, Physcomitrella patens; Sm, Selaginella moellendorfii.

respectively, in response to $200 \mathrm{mM}$ Nacl stress (Figure 4). Overall, $H s C B L 8$ was expressed to significantly higher levels in both shoots and roots than that in $H v C B L 8$. The expression profile of both the genes in the shoot generally followed a sigmoid curve in general. The expression level was enhanced in the first hour of $\mathrm{NaCl}$ application, reaching its peak after $6 \mathrm{~h}$ and then gradually declining with prolonged salt stress from 12 to $48 \mathrm{~h}$, respectively (Figure $\mathbf{4 A}$ ). In the roots, the expression of the CBL8s in both XZ166 and CM72 was greatly suppressed (Figure 4B) during first hour of $\mathrm{NaCl}$ treatment. However, both the genes were highly expressed at 3 and $6 \mathrm{~h}$ of stress treatment. Afterward, a gradual decline was observed in the expression pattern after up to $48 \mathrm{~h}$ of stress treatment. However, significant differences in transcriptional levels were observed between $H v C B L 8$ and $H s C B L 8$ at 3, 24, and $48 \mathrm{~h}$ in the roots (Figure 4B), revealing the variation in the degree of sensitivity of these genes to salt stress. 


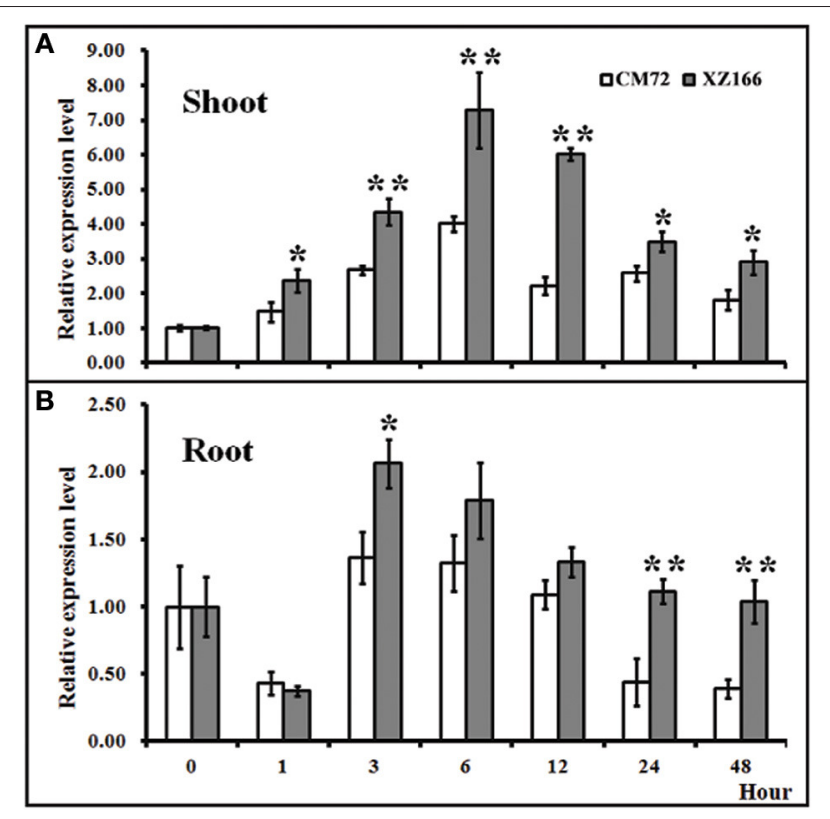

FIGURE 4 | Relative expression levels of CBL8 between XZ166 and CM72 plants treated with $200 \mathrm{mM} \mathrm{NaCl}$. (A) Shoot, and (B) root. The expression level for $\mathrm{O}$ treatment was set to 1. Values include the means of three independent replicates. *Indicates a statistically significant difference at $p<0.05$ and ${ }^{* *}$ signifies a highly significant difference compared with those of the $\mathrm{CM} 72$.

\section{HsCBL8 Transgenic Rice and Its Response to Salt Stress}

To study the role of $H s C B L 8$ in rice, an Agrobacterium strain EHA105 harboring the plasmid PCAMBIA1300-35S-HsCBL8, was transformed into rice $\mathrm{ZH} 11$ using embryo calli induced from mature seeds. A Southern blot analysis using two restriction enzymes, Hind III and EcoR I, revealed the presence of two copies (T1-1 and T1-3) of the T1 transgenic line of rice (Figure 5). Of these transgenic plants, 20 T2 seedlings of T1-1 and 20 T2 seedlings T1-3 were verified by PCR and resulted in the detection of 9 homozygous transgene (35S-HsCBL8) plants with $679 \mathrm{bp}$ band length. Furthermore, T3 seeds from T2 homozygous lines namely T2-1-3 (L1) and T2-3-9 (L2) (Figure S1), were selected for further analysis to evaluate the functional attributes of the gene for its tissue-specific expression.

To evaluate the possible role of $H s C B L 8$ in salt tolerance, the seedling growth and morphology of the transgenic rice lines (L1 and L2) were compared with that of the control (ZH11) plants (Figure 6). The comparison was conducted under normal and $125 \mathrm{mM} \mathrm{NaCl}$ stress conditions. We found insignificant differences in seed germination (Figure 6A) and seedling fresh weight (Figure 6C) between the transgenic and $\mathrm{ZH} 11$ plants under the normal growth conditions as evident from the seedling growth (Figure 6B). By contrast, fairly obvious and significant variations in seed germination rate as well as seedling fresh weight were observed between the transgenic lines and nontransgenic ZH11 under $125 \mathrm{mM} \mathrm{NaCl}$ stress (Figures 6A,C). The overall germination rate of both transgenic and $\mathrm{ZH} 11$ seeds

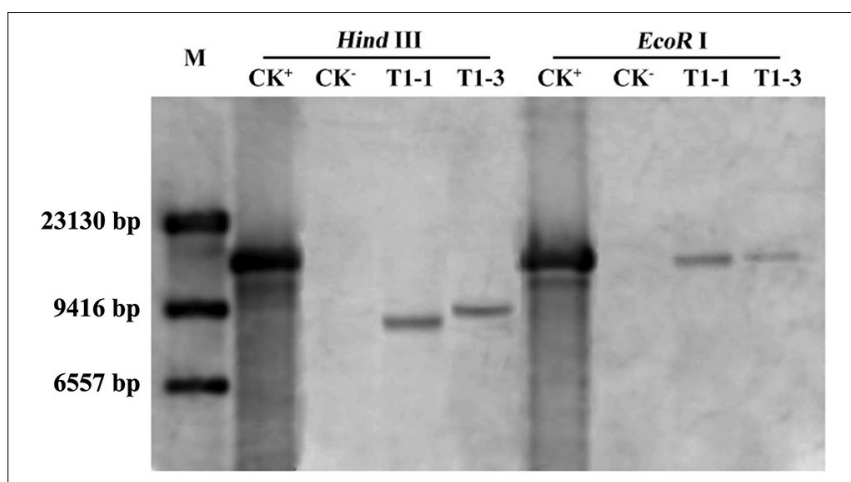

FIGURE 5 | Southern blot analysis of T1 transgenic rice plants. M, DNA marker ( $\lambda$-DNA/Hind III); $\mathrm{CK}^{+}$, pCAMBIA1300-35S-HsCBL8 (12.9 kbp); $\mathrm{CK}^{-}, \mathrm{ZH} 11$; T1-1 and T1-3 selected transgenic lines with one copy of HsCBL8 integrated into the rice genome.

were reduced under salt stress relative to that of the untreated seeds. However, the lines L1 and L2 thrived best at around $75 \%$ germination which was $20 \%$ higher than that of $\mathrm{ZH} 11$ (Figure 6A). This finding was evident from the stunted growth of the radicles and plumules of the $\mathrm{ZH} 11$ seedlings under salt stress (Figure 6B). Moreover, the rate of water loss from the transgenic lines was significantly lower than that of $\mathrm{ZH} 11$ when the application of salt stress was prolonged from 0 to $24 \mathrm{~h}$. Obvious differences between the fresh weights of seedlings of transgenic lines and ZH11 were observed at $16(p<0.05)$ and $24 \mathrm{~h}(p<0.01)$ of salt stress (Figure 6C). Furthermore, we tested salt tolerance in the plants at the well-grown vegetative stage. We then planted the seedlings of L1, L2 and ZH11 for 30 days in normal conditions hydroponically. After 30 days of growth, we applied $125 \mathrm{mM} \mathrm{NaCl}$ stress, initially for 2 days, 4 days, and finally 6 days (Figure 6D). The affects of $\mathrm{NaCl}$ treatment were significantly prominent on the leaves of the $\mathrm{ZH} 11$ plants, especially on the older leaves. The degree of severity of the effect was increased with the exposure time of the ZH11 plants to the treatment from 2 to 6 days compared with that in the transgenic lines. This effect was manifested as withering of older leaves, increased water loss, and curling of young leaves in the ZH11 plants compared with those in the L1 and L2 plants. The transgenic plants showed better performance as exhibited by the strong vitality of the top new leaves, even after 6 days of $\mathrm{NaCl}$ treatment (Figure 6D). These results indicate the obvious role of $H s C B L 8$ in salt tolerance.

\section{Role of HsCBL8 in the Salt Stress Response in Transgenic Rice}

Generally, the accumulation of compatible osmolytes such as proline, are associated to the stress tolerance of the corresponding plant (Ahmed et al., 2013; Mekawy et al., 2015). Meanwhile, quantification of MDA concentrations and REL is considered as an efficient indicator of the structural integrity of the plant membranes in response to abiotic factors, such as salt stress. To evaluate the functional attributes of overly expressed $\mathrm{HsCBL8}$ for rice tolerance against salt stress, we analyzed the proline 

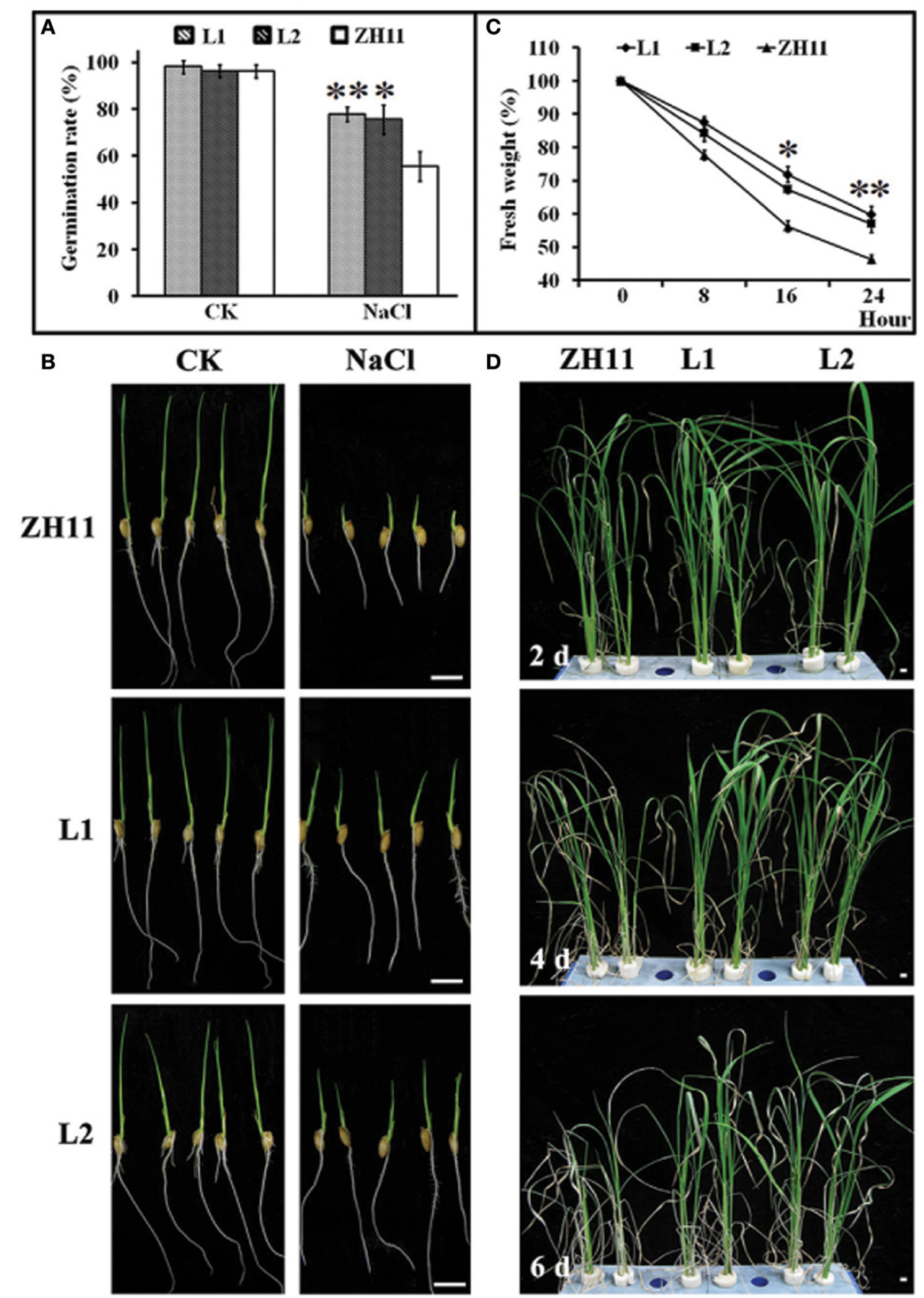

FIGURE 6 | Phenotypic changes of transgenic rice lines induced by salt stress. (A) Germination rate of seeds treated with $125 \mathrm{mM}$ NaCl for 5 days, and morphological characteristics of rice young seedlings (B). (C) Water loss, 2 week pre-cultured plants were treated with $125 \mathrm{mM}$ NaCl. (D) Photos of rice shoots with treatment of $125 \mathrm{mM} \mathrm{NaCl}$, the seedlings were pre-cultured for 30 days in normal conditions. Values include the means $\pm \mathrm{standard}$ deviation $(\mathrm{SD})(n=3)$. ${ }^{\star}(p<0.05)$ and ${ }^{* \star}(p<0.01)$ indicate that these values were statistically significantly and highly significantly different respectively, compared with that of the Z $\mathrm{H} 11$. Bar $=1 \mathrm{~cm}$. CK, normal condition; $L 1$ and $L 2$, transgenic lines.

and MDA concentrations, and rate of REL. Accordingly, the $H s C B L 8$ overexpression in the transgenic rice resulted in the accumulation of 35 and $56 \%$ additional proline content in the L1 and L2 lines, respectively, after $24 \mathrm{~h}$ of salt stress compared with that in ZH11 (Figure 7A). Moreover, plant exposure to plants to salt stress for $72 \mathrm{~h}$ resulted in an overall increase in proline content in both the transgenic and $\mathrm{ZH} 11$ plants compared with those in $24 \mathrm{~h}$. Even so, 33\% and 25\% accumulation of additional proline content was observed in L1 and L2 respectively, relative to that in $\mathrm{ZH} 11$. This result indicates the possible role of $\mathrm{HsCBL8}$ in salt tolerance. On the contrary, $H s C B L 8$ overexpression significantly reduced the MDA content and REL in the transgenic 
lines compared with the non-transgenic ZH11 plants under salt stress. This reduction in MDA content was in the order of $36 \%$ (in both transgenic lines) at $24 \mathrm{~h}$, but 31 and $29 \%$ in L1 and $\mathrm{L} 2$, respectively, at $72 \mathrm{~h}$ of salt stress compared with the contents in ZH11 (Figure 7B). Similarly, 33 and $46 \%$ reduction in REL was observed in L1 and L2 respectively, at $24 \mathrm{~h}$ of salt treatment, whereas, reduction of $23 \%$ and $24 \%$ reduction in REL was noted in L1 and L2, respectively, at $72 \mathrm{~h}$ of salt stress compared with that in the ZH11 plants (Figure 7C).

\section{$\mathrm{Na}^{+}$and $\mathrm{K}^{+}$Contents in the $\mathrm{HsCBL8}$ Transgenic Rice}

Generally, the ability of a crop variety to inhibit the uptake of potentially toxic ions such as $\mathrm{Na}^{+}$and preferential uptake of $\mathrm{K}^{+}$ to keep the balance between ions is regarded as a desirable trait for salt tolerance. To investigate whether $H s C B L 8$ could induce the salt tolerance trait in transgenic rice, we analyzed the status of $\mathrm{Na}^{+}$and $\mathrm{K}^{+}$ions and their comparative ratio in roots and shoots under control, as well as salt stress conditions. Plants of both transgenic as well as $\mathrm{ZH} 11$ pre-grown for 30 days under normal condition were exposed to $125 \mathrm{mM} \mathrm{NaCl}$ stress for 6 days. After 6 days, analysis of the ions revealed insignificant differences in $\mathrm{Na}^{+}$and $\mathrm{K}^{+}$concentration among unstressed transgenic lines and $\mathrm{ZH} 11$. By contrast, under salt stress, $\mathrm{Na}^{+}$accumulation was generally noted at higher content in the shoots than in the roots in either of the transgenic lines and ZH11 plants. However, the $\mathrm{Na}^{+}$ contents in ZH11 plants were significantly higher in the shoots $(42 \%)$ as well as the roots $(18.5 \%)$ than in both of the transgenic lines (Figure 7D). On the other hand, salt stress induced a slight change in root and shoot $\mathrm{K}^{+}$contents between the transgenic lines and $\mathrm{ZH} 11$ plants applied with or without $\mathrm{NaCl}$ treatment (Figure 7E). Consequently, the $\mathrm{Na}^{+} / \mathrm{K}^{+}$ratio in both shoot and root was lower in transgenic lines than that in $\mathrm{ZH} 11$ plants (Figure 7F), indicating that the overexpression of $H s C B L 8$ in rice could regulate and induce salt tolerance.

\section{Expression Levels of Some Stress Responding Genes in the Transgenic Rice Harboring $\mathrm{HsCBL8}$}

To investigate whether $H s C B L 8$ could regulate the salt-responsive genes in rice, we performed the gene expression profiling of the $35 S-H s C B L 8$ transgenic lines (L1 and L2) in comparison with the non-transgenic plants under normal conditions and salt stress. The genes selected were either specifically salt responsive (OsSOS2/OsCIPK24, OsNHX1, and OsSOS1) and/or responsive to multiple stresses (abiotic or biotic) (OsCIPK15, OsRD29A, and OsDREB2A). Under normal growth conditions (unstressed, $0 \mathrm{~h}$ ), we observed extremely weak expression, as well as insignificant variations in the transcriptional levels of all the selected genes in both ZH11 and transgenic plants. This result indicates that $H s C B L 8$ exerted an almost negligible interaction with these genes (Figures 8A-F) in the unstressed environment. At the onset of stress application $(125 \mathrm{mM} \mathrm{NaCl})$ initially for $3 \mathrm{~h}$, the overall relative expression level of the genes was enhanced relative to that in the unstressed plants. However, the difference between the transgenic lines and ZH11 was insignificant. Moreover, duration of salt stress exposure was prolonged to $6 \mathrm{~h}$, all the genes were found substantially up-regulated compared with the unstressed plants $(0 \mathrm{~h})$ or those subjected to salt stress for $3 \mathrm{~h}$. However, a a comparison between the transgenic lines and $\mathrm{ZH} 11$ at $6 \mathrm{~h}$ of salt stress revealed that the overexpression of $H s C B L 8$ in both the transgenic rice lines up-regulated some of the genes, such as OsSOS2/OsCIPK24, OsCIPK15, and OsRD29A, to a higher level than that in ZH11 (Figures 8A,B,E). Even so, the overall variation was insignificant, similar to the one observed in plants exposed to $3 \mathrm{~h}$ of salt stress or the untreated plants. These results indicate that the overexpression of $H s C B L 8$ in rice could not affect the regulation of salt-responsive genes significantly, showing the negligible interaction of $H s C B L 8$ with all the selected genes expressed in response to salt stress.

\section{GUS Activity Driven by the HsCBL8 Promoter in Response to Abiotic Stress in Transgenic Arabidopsis}

To have more detailed perspective of expression pattern of $H s C B L 8$ in response to various abiotic stresses, the promoter fragment of $H s C B L 8$ was fused with the GUS reporter gene and transferred to Arabidopsis to develop $\mathrm{HsCBL}_{\mathrm{Pro}_{\mathrm{O}}-G U S \text { transgenic }}$ lines (Figure 1B). The expression of GUS activity was examined in 17 independent transgenic lines. Except for three lines (with zero GUS activity), the other 14 lines exhibited similar tissuespecific expression pattern. However, the intensity of the colors varied among lines, probably because of the position effect. The GUS expression pattern of a representative line (TGUS-7) is presented herein (Figures 9A-J). Under normal conditions, GUS signals were extremely weak in the cotyledon apex at the second day after germination (Figure 9A), whereas, the hypocotyl stele was stained light blue at the third day (Figure 9B), showing the activity of GUS promoted in hypocotyl and cotyledons (Figure 9C) and further strengthened in the vascular bundles of elder rosette leaves (Figures 9D,J). However, no activity was observed in the newly formed root tissues, including lateral root tips (Figures 9D,J), instead the blue stain was observed within the root stele tissue (Figure 9J) and the junction tissue of tap and lateral roots (Figure 9J). Furthermore, GUS activity at the reproductive phase was detected in sepals, filaments, and tissues between the style and stigma, and tissues between the silique and silique petiole but no GUS signal was observed in the petals and seeds (Figures 9E-H).

Some cis elements in the HsCBL8 promoter sequence predicted by PlantCARE, such as ABRE and MBS (Table 1), normally respond to ABA signal and drought stress, respectively. To evaluate the response of the $H s C B L 8$ gene to $\mathrm{ABA}$, drought, $\mathrm{NaCl}$ and cold stress, GUS activity was measured by fluorometric assay (Figure 9K). Four-week-old Arabidopsis seedlings were supplemented with $100 \mu \mathrm{M}$ ABA, 20\% PEG6000, and $100 \mathrm{mM}$ $\mathrm{NaCl}$ to apply $\mathrm{ABA}$, drought and salt stress, respectively. For cold treatment, the seedlings were transferred to a growth chamber under dark conditions at $4^{\circ} \mathrm{C}$. GUS activity was assayed after $12 \mathrm{~h}$ treatment. Accordingly, compared with untreated plants, GUS activity was observed to significantly $(p<0.01)$ higher levels in the plants treated with ABA (294\%), $\mathrm{NaCl}(230 \%)$, and 


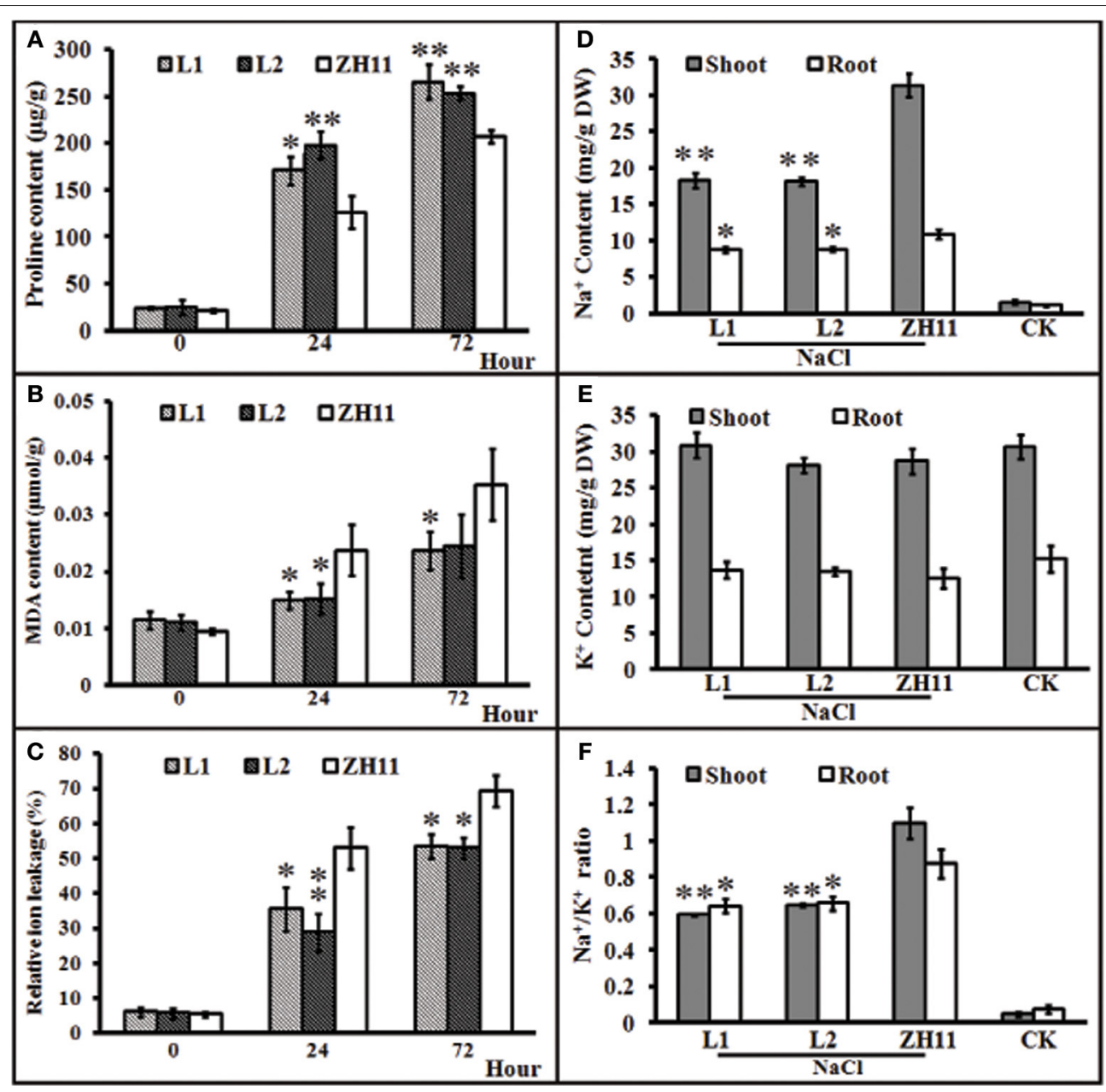

FIGURE 7 | Characteristics of transgenic rice lines and ZH11 treated with salt stresses. (A-C) , physiological indexes reflecting salt tolerance: (A) proline content, (B) MDA content, and $\mathbf{( C )}$ relative ion leakage. Plants pre-cultured for 2 weeks were treated with $125 \mathrm{mM} \mathrm{NaCl}$. (D-F), Na ${ }^{+}$and $\mathrm{K}^{+}$contents (mg/g DW) of shoots and roots of transgenic and $\mathrm{ZH} 11$ plants. (D) $\mathrm{Na}^{+}$and (E) $\mathrm{K}^{+}$levels and (F) $\mathrm{Na}^{+} / \mathrm{K}^{+}$ratio. $\mathrm{Na}^{+}$and $\mathrm{K}^{+}$contents were measured after 6 days of $125 \mathrm{mM}$ $\mathrm{NaCl}$ treatment. The treated plants were pre-cultured for 30 days. Values include the means $\pm \mathrm{SD}(n=4)$. ${ }^{*}(p<0.05)$ and ${ }^{\star *}(p<0.01)$ indicate that these values were statistically significantly and highly significantly different, respectively, compared with that of ZH11 or CK. CK and ZH11 growing in normal conditions; L1 and L2, transgenic rice lines.

PEG6000 ( $p<0.05 ; 205 \%)$, respectively, whereas, an increase of only $43 \%$ was obtained with cold treatment, indicating the possible response of $H s C B L 8$ to these stresses.

\section{DISCUSSION}

Hordeum spontanum, derived from Qinghai-Tibet Plateau (origin center of the cultivated barley) is known as a highly salttolerant species (Dai et al., 2012; Wu et al., 2013). Being a member of same crop family, studies on the elite genes of this species in rice could help us better understand of the salt-tolerance mechanisms in wild barley. To obtain insight about the salt stress responses in rice related to elite gene(s) from wild barley, we selected the $H s C B L 8$ gene and thoroughly analyzed its functional relations with other genes in response to the salt stress regime. Initially, we conducted the phylogenetic analysis of $H s C B L 8$ and revealed that the encoded protein belongs to the group of $\mathrm{CBL}$ proteins only modified with $\mathrm{N}$-myristoylation or S-acylation (Batistic et al., 2012), (Figure 2A). Thus, these proteins are involved in close phylogenetic relationships with the members of group II-I-I-II (Figure 2) besides 10 other CBL proteins. This group was clustered into a clade defined as a transmembrane (TM) helix (Kleist et al., 2014) in accordance with AtCBL10, which harbors a unique transmembrane-spanning region (Kim et al., 2007). Moreover, ZmCBL10, OsCBL9, SbCBL7, and HsCBL8 also harbor long N-terminal extensions (Figure 2A), indicating that the long $\mathrm{N}$-terminal amino-acid sequence of HsCBL8 may be involved in sub-cellular localization. However, we could not find the transmembrane domain in the HsCBL8 protein sequence similar to that in AtCBL10. Therefore, further investigation must to be conducted to confirm the assumption. 


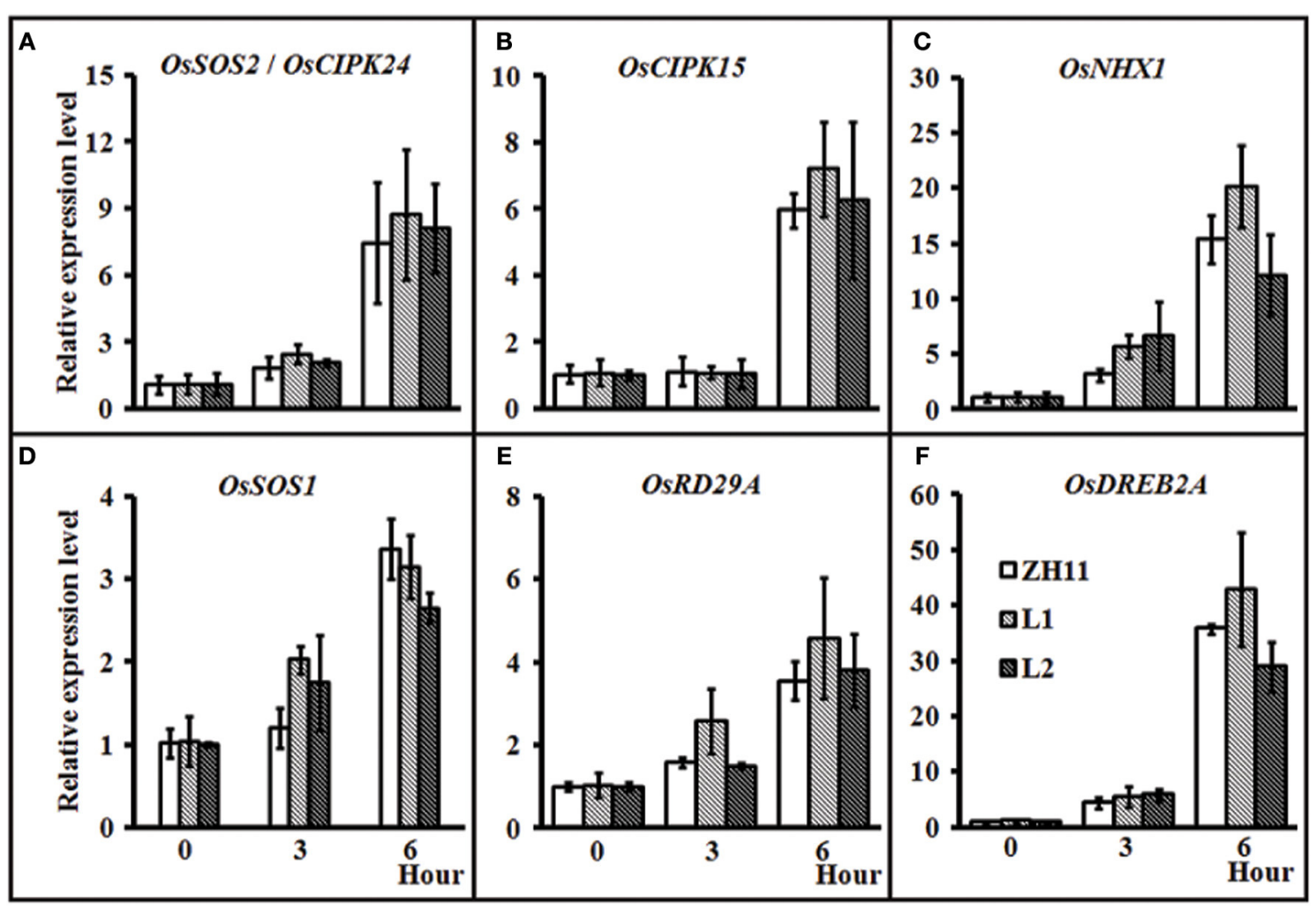

FIGURE 8 | Relative expression of some stress-responsive genes in rice ZH11 and two transgenic lines with treatment of $125 \mathrm{mM}$ NaCl for 0, 3, and $\mathbf{6 h}$. The plants were pre-cultured for 3 weeks in hydroponic solution. The expression level of each gene for WT (0 h) was set to 1 . Values include the means \pm SD $(n=3)$. Actin1 (NCBI ID: NC_008396) was used as reference gene. NCBI ID: OsSOS2 (A), DQ248963; OsCIPK15 (B), AB264037; OsNHX1 (C), AB021878; OsSOS1 (D), AY785147; OsDREB2A (E), JQ341059, and OsRD29A (F) (Rao et al., 2011).

In general, each CBL protein harbors four EF-hand motifs (Figures 2A,B), but not all of the CBL proteins contain four canonical EF-hand motifs. For instance, five CBL proteins in Arabidopsis (CBL2, CBL3, CBL4, CBL5, and CBL8) do not possess any canonical EF hand, whereas, CBL6, CBL7 and CBL10 contain one and CBL1 and CBL9 contain two canonical EF hands (Batistic et al., 2012). Herein, both HsCBL8 and HvCBL8 lack the fourth EF hands (Figure 2A). Moreover, the structural and numeral differences in the EF hands demonstrate variations in $\mathrm{Ca}^{2+}$ binding affinity and interactions between the $\mathrm{CBL}$ and CIPK proteins. For example, crystal structure analyses of AtCBL2 and AtCBL4 revealed that AtCBL2 bound only to CIPK14 with four $\mathrm{Ca}^{2+}$ ions in all four EF hands (Akaboshi et al., 2008), whereas, AtCBL4 bound only to CIPK24 with two $\mathrm{Ca}^{2+}$ ions in two EF hands (Sánchez-Barrena et al., 2007). Therefore, the model representing the cooperative binding of the EF hand and $\mathrm{Ca}^{2+}$ ion in HsCBL8 could not be deduced from the current results. This finding suggests that some known downstream factors of CBLs were not regulated by $H s C B L 8$ (Figure 9). Instead $\mathrm{HsCBL} 8$ might interact with other factors to regulate downstream genes responding to salt stress in transgenic rice.

To verify this hypothesis, we investigated the growth performance of transgenic rice lines with $H s C B L 8$ expression in response to salt stress. We observed that the constitutive expression of $\mathrm{HsCBL8}$ significantly improved the tolerance against salt stress in rice. Germination rate was the first index that showed the obvious role of $H s C B L 8$ against salt stress in the transgenic rice treated with $125 \mathrm{mM} \mathrm{NaCl}$ (Figure 6A). These findings followed the similar trends reported for other $C B L s$ in various plant species, such as the transgenic Arabidopsis harboring 35S-AtCBL5 (Cheong et al., 2010) and the poplar containing 35S-PeCBL10 (Li D. D. et al., 2013). Moreover, scholars reported that $O s C B L 2$ may be involved in a GA-signaling pathway that leads to the vacuolation of the aleurone cell (Hwang et al., 2005). Meanwhile, the attributes of AtCBL1 in terms of positive response to gibberellins (Li Z.-Y. et al., 2013) and negative response to ABA (Pandey et al., 2008) during seed germination and seedling development could provide evidence supporting the similar characteristics of $H s C B L 8$ under the salt stress condition. The overexpression of $H s C B L 8$ in our study also decreased $\mathrm{Na}^{+}$uptake partly in rice (Figures 7D-F). Moreover, AtCBL10, which shares the same cluster with $H s C B L 8$ (Figure 3), responded similarly to salt stress by modulating the activities of $\mathrm{Na}^{+}$transporters (Kim et al., 2007; Quan et al., 2007). AtCBL10's homologs PeCBL10 (Li D. D. et al., 2013) and NsylCBL10 (Dong et al., 2015) in roots, whereas, PtCBL10A and PtCBL10B (Tang et al., 2014) in shoots also showed salt tolerance by regulating 

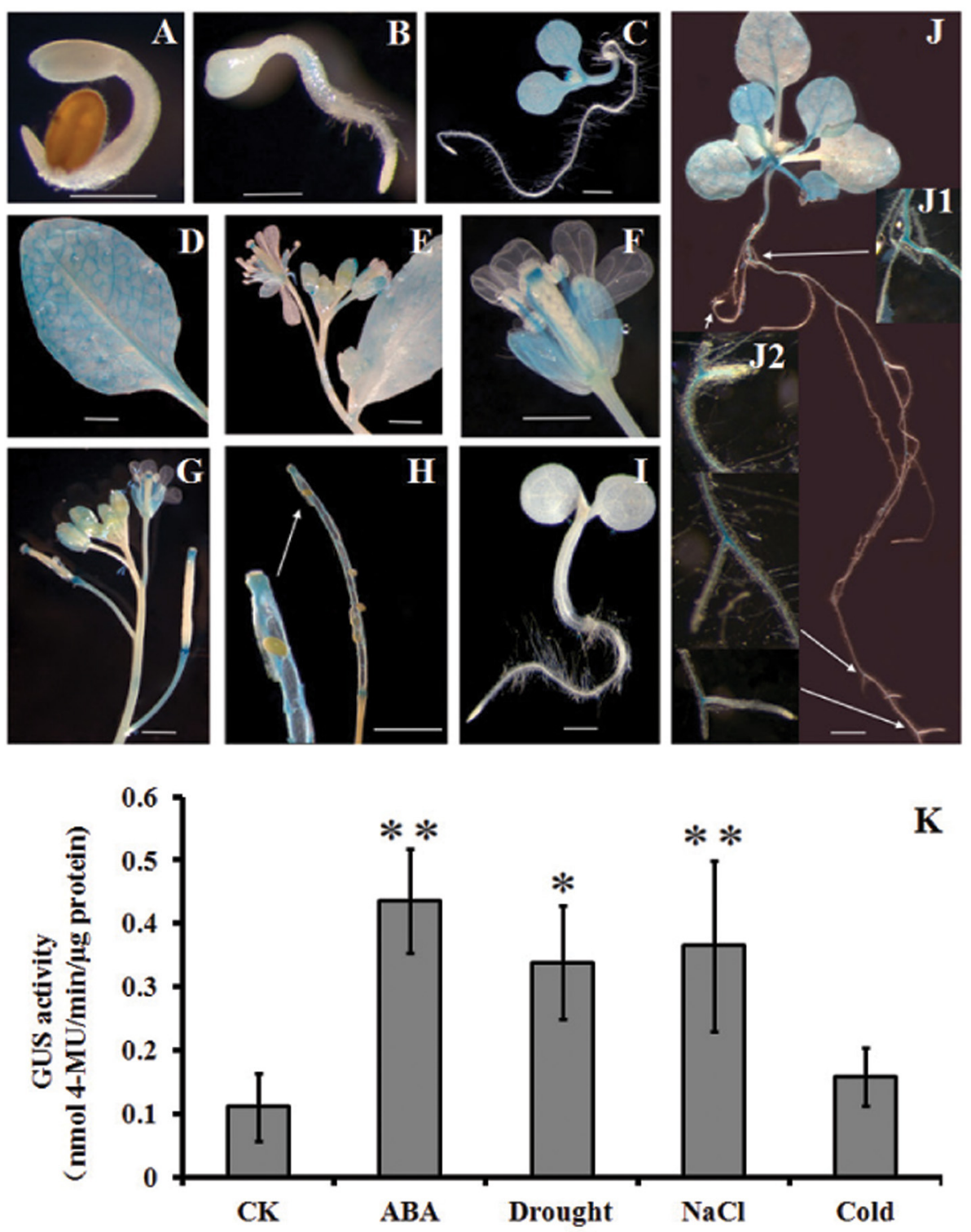

FIGURE 9 | Histochemical analysis of GUS activity in transgenic Arabidopsis plants. (A-J) GUS staining at different developmental stages; (K), GUS activity responding to ABA, drought, $\mathrm{NaCl}$, and cold treatments. (A) 2-day-old seedlings, (B) 3-day-old seedling, (C) 6-day-old seedling, (D) rosette leaf, (E,F) flowers, (G) young siliques, (H) mature siliques, (I) Col-0, and (J) 2-week-old seedlings. (K) 4-week-old seedlings supplemented with $100 \mu$ M ABA, $20 \%$ PEG6000, and 100 mM $\mathrm{NaCl}$. For cold treatment, the seedlings were transferred to a $4^{\circ} \mathrm{C}$ growth chamber in the dark. GUS activity was assayed after $12 \mathrm{~h}$ treatment. The values are expressed as means $\pm S D(n=4)$. ${ }^{*}$ Indicates statistically significant difference at $(p<0.05)$ and ${ }^{*}$ indicates a highly statistically significant difference at $(p<0.01)$ compared with CK. Bar $=5 \mathrm{~mm}$. The line with arrow shows the magnified tissue portion.

$\mathrm{Na}^{+}$balance, indicating that $\mathrm{HsCBL8}$ might regulate some $\mathrm{Na}^{+}$ transporters or channels involved in the efflux of excess $\mathrm{Na}^{+}$ under salt stress. However, $\mathrm{K}^{+}$uptake was slightly affected in the transgenic rice with $\mathrm{HsCBL8}$ (Figure 7E). Recent evidence showed that AtCBL10 may directly compete with CIPK23 for binding to AKT1 and negatively modulate AKT1 activity (Ren et al., 2013) but AtCBL1/9-CIPK23-AKT1 ( $\mathrm{K}^{+}$transporter) might enhance $\mathrm{K}^{+}$uptake under low- $\mathrm{K}^{+}$conditions (Xu et al., 2006; Li et al., 2014). These findings suggested that $H s C B L 8$ may lessen the antagonism of high $\mathrm{Na}^{+}$to $\mathrm{K}^{+}$uptake. Nevertheless, the underlying mechanism remains unknown. Unexpectedly, the transcriptional levels of some known downstream factors of CBLs in transgenic rice were not regulated by $H_{s} C B L 8$ (Figure 8), including the $\mathrm{Na}^{+}$transporters $O s N H X 1$ and OsSOS1. Thus, HsCBL8 might interact with other known or unknown factors for improving salt tolerance, membrane protection (Figures 7B,C), promoting proline accumulation (Figure 7A), and so on.

To confirm the functional attributes of $H s C B L 8$ in plant growth and development, we conducted GUS staining. Staining 
under normal conditions resulted in the appearance of blue stains in cotyledon, hypocotyl stele, leaves, root stele, and at the junction of the lateral root, sepal, filament, tissues between style and stigma, and tissue between silique and silique petiole (Figures 9A-J). Thus, the localization of $H s C B L 8$ was found similar to that of other CBLs. For instance, the presence of $A t C B L 3$ is in roots, leaves, siliques and seeds (Tang et al., 2012); OsCBL2 is in the aleurone layer induced by GA (Hwang et al., 2005); whereas, AtCBL1, AtCBL2, AtCBL3, and AtCBL9 were involved in seed germination and seedling and pollen development (Pandey et al., 2008; Li D. D. et al., 2013; Mähs et al., 2013; Zhou et al., 2015). Moreover, the overexpression of soybean $G m C B L 1$ promoted hypocotyl elongation under normal light conditions in Arabidopsis (Li Z.-Y. et al., 2013). HsCBL8 may also involve light and GA response cis elements in its promoter sequence (Table 1), but few is known about this aspect and further study is needed.

Some genes from CBL family were considered stress responsive either directly or indirectly, by interacting with other genes (Kim, 2013). Therefore, the expression levels of the genes specifically responsive to salt stress, including OsSOS2/OsCIPK24, OsNHX1, and OsSOS1 (Fukuda et al., 1999), were analyzed. Besides the genes expressed under salt-specific stress, microbe-associated molecular pattern-induced defense genes (OsCIPK15, Kurusu et al., 2010, ABA- and osmotic-stressresponsive genes (Rao et al., 2011), and drought-, high saltand cold-stress-responsive (OsDREB2A, Dubouzet et al., 2003 genes were also analyzed. As evident in the results (Figure 4), the application of salt stress induced $H s C B L 8$ expression in the wild barley. Notably, the expression of HsCBL8 declined significantly at the first hour in root and increased significantly afterwards. Possibly, it takes time for plants adapting themselves to adverse environments, a process described as "shook" in some literatures (Munns and Tester, 2008; Shavrukov, 2013). The promoter analysis of $H s C B L 8$ revealed the presence of some stress response cis domains (Table 1), including ABA- and drought-response sequences, which was confirmed from the GUS activity analysis, as the promoter was activated by $\mathrm{ABA}$, drought, and salt stress (Figure 9K), indicating the involvement of $H s C B L 8$ in upstream signaling pathway responding to these abiotic stresses.

$\mathrm{ABA}$ is widely considered as a stress-response phytohormone. A study on plants with CBL mutation revealed that AtCBL9 was more sensitive to exogenous $\mathrm{ABA}$ and could regulate $\mathrm{ABA}$ bio-synthesis as the young seedlings of cbl9 mutant accumulated additional ABA (Pandey et al., 2004). However, the plants overexpressing $A t C B L 5$ did not alter their response to ABA (Cheong et al., 2010), indicating that AtCBL5 may regulate downstream genes independent from ABA. Moreover, we reported that AtCIPK15 could coordinate with several CBL proteins responding to $A B A$, including AtCBL1, 2, 3, 5, 8, and 9 (Batistic et al., 2012; Kim, 2013). These findings could suggest that $H s C B L 8$ might enhance tolerance against salt stress in rice by acting antagonistically to ABA biosynthesis or signaling. These observations were further confirmed when the overexpression of $\mathrm{HsCBL8}$ improved seed germination ratios in rice (Figure 6A). Furthermore, $\mathrm{HsCBL}_{3}$ might regulate GA signaling against $\mathrm{ABA}$.

In conclusion, $H s C B L 8$ derived from Qinghai-Tibetan wild barley was overexpressed in transgenic rice. This gene exhibited a significantly increased tolerance to high salinity through the systemic regulation of seed germination, proline accumulation, plasma membrane protection, and decreased overall $\mathrm{Na}^{+}$uptake. No defect was observed in the germination, seedling, and reproductive stages of the transgenic plants under salt stress. This finding indicated that $H$. spontanum from Qinghai-Tibet plateau can provide a significant gene pool for cereal crop improvement (Ellis et al., 2000; Dai et al., 2012). Our study successfully demonstrated the involvement of $H s C B L 8$ in regulating various physiological processes that induce salt stress tolerance in rice. Our study could be used as a basis for further research on the potential functional attributes of $H s C B L 8$ in response to other abiotic stress factors and its interaction with other unknown factors.

\section{AUTHOR CONTRIBUTIONS}

WG, LJ, and GZ conceived and designed the experiment and contributed reagents/materials/analysis tools. WG and TC conducted the experiments. WG, TC and $\mathrm{NH}$ analyzed the data. WG, TC, LJ and NH wrote the manuscript. WG, TC, NH, GZ, and $L J$ reviewed, edited and approved the manuscript.

\section{FUNDING}

This work was supported by the Zhejiang Provincial Natural Science Foundation of China [LY13C130001]; the Science Foundation of Zhejiang Sci-Tech University [14042008-Y]; the Zhejiang Provincial Top Key Discipline of Biology [2012A03-C], and Jiangsu Collaborative Innovation Center for Modern Crop Production.

\section{ACKNOWLEDGMENTS}

We thank Ms. Mei Li and Mr. Xianyin Zhang for their technical assistance, and EnPaper company for language improvement.

\section{SUPPLEMENTARY MATERIAL}

The Supplementary Material for this article can be found online at: http://journal.frontiersin.org/article/10.3389/fpls.2016. 01678/full\#supplementary-material

Table S1 | Primers used in this program.

Table S2 | Protein sequences of CBLs used in phylogenetic analysis.

Figure S1 | Screening of homozygous T2 transgenic plants by PCR using: (A) 679 bp sequence of $H s C B L 8$, and (B) RT-PCR analysis of the HsCBL8 T3 transgenic lines using 575 bp sequence of $H s C B L 8$, and OsGAPDH (BCBI ID: NM_001067432) as reference gene. Six T3 seeds (B) come from T2 line T2-1-3 and T2-3-9 in (A), respectively. M, DNA marker. $\mathrm{CK}^{+}$, PCAMBIA1300-35S-HsCBL8; CK ${ }^{-}$, ZH11. 


\section{REFERENCES}

Ahmadi-Ochtapeh, H., Soltanloo, H., Ramezanpour, S. S., Naghavi, M. R., Nikkhah, H. R., and Yoosefi Rad, S. (2015). QTL mapping for salt tolerance in barley at seedling growth stage. Biol. Plantarum 59, 283-290. doi: 10.1007/s10535-015-0496-Z

Ahmed, I. M., Cao, F., Zhang, M., Chen, X., Zhang, G., and Wu, F. (2013). Difference in yield and physiological features in response to drought and salinity combined stress during anthesis in tibetan wild and cultivated barleys. PLoS ONE 8:e77869. doi: 10.1371/journal.pone.0077869

Akaboshi, M., Hashimoto, H., Ishida, H., Saijo, S., Koizumi, N., Sato, M., et al. (2008). The crystal structure of plant-specific calcium-binding protein AtCBL2 in complex with the regulatory domain of AtCIPK14. J. Mol. Biol. 377, 246-257. doi: 10.1016/j.jmb.2008.01.006

Albrecht, V., Ritz, O., Linder, S., Harter, K., and Kudla, J. (2001). The NAF domain defines a novel protein-protein interaction module conserved in $\mathrm{Ca}^{2+}$-regulated kinases. EMBO J. 20, 1051-1063. doi: 10.1093/emboj/20.5.1051

Batistic, O., Rehers, M., Akerman, A., Schlucking, K., Steinhorst, L., Yalovsky, S., et al. (2012). S-acylation-dependent association of the calcium sensor CBL2 with the vacuolar membrane is essential for proper abscisic acid responses. Cell Res. 22, 1155-1168. doi: 10.1038/cr.2012.71

Chen, J. H., Sun, Y., Sun, F., Xia, X. L., and Yin, W. L. (2011). Tobacco plants ectopically expressing the Ammopiptanthus mongolicus AmCBL1 gene display enhanced tolerance to multiple abiotic stresses. Plant Growth Regul. 63, 259-269. doi: 10.1007/s10725-010-9523-4

Chen, L., Ren, F., Zhou, L., Wang, Q.-Q., Zhong, H., and Li, X.-B. (2012). The Brassica napus calcineurin B-Like 1/CBL-interacting protein kinase 6 (CBL1/CIPK6) component is involved in the plant response to abiotic stress and ABA signalling. J. Exp. Bot. 63, 6211-6222. doi: 10.1093/jxb/ers273

Cheong, Y. H., Sung, S. J., Kim, B.-G., Pandey, G. K., Cho, J.-S., Kim, K.-N., et al. (2010). Constitutive overexpression of the calcium sensor CBL5 confers osmotic or drought stress tolerance in Arabidopsis. Mol. Cells 29, 159-165. doi: 10.1007/s10059-010-0025-Z

Dai, F., Nevo, E., Wu, D., Comadran, J., Zhou, M., Qiu, L., et al. (2012). Tibet is one of the centers of domestication of cultivated barley. Proc. Natl. Acad. Sci. U.S.A. 109, 16969-16973. doi: 10.1073/pnas.1215265109

Das, G., and Rao, G. J. N. (2015). Molecular marker assisted gene stacking for biotic and abiotic stress resistance genes in an elite rice cultivar. Front. Plant Sci. 6:698. doi: 10.3389/fpls.2015.00698

Dong, L., Wang, Q., Manik, S. M. N., Song, Y., Shi, S., Su, Y., et al. (2015). Nicotiana sylvestris calcineurin B-like protein NsylCBL10 enhances salt tolerance in transgenic Arabidopsis. Plant Cell Rep. 34, 2053-2063. doi: 10.1007/s00299-0151851-4

Dubouzet, J. G., Sakuma, Y., Ito, Y., Kasuga, M., Dubouzet, E. G., Miura, S., et al. (2003). OsDREB genes in rice, Oryza sativa L., encode transcription activators that function in drought-, high-salt- and cold-responsive gene expression. Plant J. 33, 751-763. doi: 10.1046/j.1365-313X.2003.01661.x

Ellis, R. P., Forster, B., Robinson, D., Handley, L., Gordon, D., Russell, J., et al. (2000). Wild barley: a source of genes for crop improvement in the 21 st century? J. Exp. Bot. 51, 9-17. doi: 10.1093/jexbot/51.342.9

Fukuda, A., Nakamura, A., and Tanaka, Y. (1999). Molecular cloning and expression of the $\mathrm{Na}^{+} / \mathrm{H}^{+}$exchanger gene in Oryza sativa. Biochim. Biophys. Acta 1446, 149-155. doi: 10.1016/S0167-4781(99)00065-2

Gallagher, S. R. (1992). "Quantitation of GUS activity by fluorometry," in GUS Protocols: Using the GUS Gene as a Reporter of Gene Expression, ed S. R. Gallagher (New York, NY: Academic Press Inc.), 47-59.

Gao, J.-P., and Lin, H.-X. (2013). "QTL analysis and map-based cloning of salt tolerance gene in rice," in Rice Protocols, ed Y. Yang (Totowa, NJ: Humana Press), 69-82.

$\mathrm{Hu}$, S., Tao, H., Qian, Q., and Guo, L. (2012). Genetics and molecular breeding for salt-tolerance in rice. Rice Genom. Genet. 3, 39-49. doi: 10.5376/rgg.2012.03.0007

Hwang, Y. S., Bethke, P. C., Cheong, Y. H., Chang, H. S., Zhu, T., and Jones, R. L. (2005). A gibberellin-regulated calcineurin B in rice localizes to the tonoplast and is implicated in vacuole function. Plant Physiol. 138, 1347-1358. doi: 10.1104/pp.105.062703

Kim, B. G., Waadt, R., Cheong, Y. H., Pandey, G. K., Dominguez-Solis, J. R., Schültke, S., et al. (2007). The calcium sensor CBL10 mediates salt tolerance by regulating ion homeostasis in Arabidopsis. Plant J. 52, 473-484. doi: 10.1111/j.1365-313X.2007.03249.x

Kim, K.-N. (2013). Stress responses mediated by the CBL calcium sensors in plants. Plant Biotechnol. Rep. 7, 1-8. doi: 10.1007/s11816-012-0228-1

Kleist, T. J., Spencley, A. L., and Luan, S. (2014). Comparative phylogenomics of the CBL-CIPK calcium-decoding network in the moss Physcomitrella, Arabidopsis, and other green lineages. Front. Plant Sci. 5:187. doi: 10.3389/fpls.2014.00187

Kolukisaoglu, U., Weinl, S., Blazevic, D., Batistic, O., and Kudla, J. (2004). Calcium sensors and their interacting protein kinases: genomics of the Arabidopsis and rice CBL-CIPK signaling networks. Plant Physiol. 134, 43-58. doi: 10.1104/pp.103.033068

Kurusu, T., Hamada, J., Nokajima, H., Kitagawa, Y., Kiyoduka, M., Takahashi, A., et al. (2010). Regulation of microbe-associated molecular pattern-induced hypersensitive cell death, phytoalexin production, and defense gene expression by calcineurin B-like protein-interacting protein kinases, OsCIPK14/15, in rice cultured cells. Plant Physiol. 153, 678-692. doi: 10.1104/pp.109.151852

Li, D. D., Xia, X. L., Yin, W. L., and Zhang, H. C. (2013). Two poplar calcineurin B-like proteins confer enhanced tolerance to abiotic stresses in transgenic Arabidopsis thaliana. Biol. Plant. 57, 70-78. doi: 10.1007/s10535-012-0251-7

Li, J., Long, Y., Qi, G.-N., Li, J., Xu, Z.-J., Wu, W.-H., et al. (2014). The Os-AKT1 channel is critical for $\mathrm{K}^{+}$uptake in rice roots and is modulated by the rice CBL1-CIPK23 complex. Plant Cell 26, 3387-3402. doi: 10.1105/tpc.114.123455

Li, R., Zhang, J., Wu, G., Wang, H., Chen, Y., and Wei, J. (2012). HbCIPK2, a novel CBL-interacting protein kinase from halophyte Hordeum brevisubulatum, confers salt and osmotic stress tolerance. Plant Cell Environ. 35, 1582-1600. doi: 10.1111/j.1365-3040.2012.02511.X

Li, Z.-Y., Xu, Z.-S., Chen, Y., He, G.-Y., Yang, G.-X., Chen, M., et al. (2013). A novel role for Arabidopsis CBL1 in affecting plant responses to glucose and gibberellin during germination and seedling development. PLoS ONE 8:e56412. doi: 10.1371/journal.pone.0056412

Li, Z. Y., Xu, Z. S., He, G. Y., Yang, G. X., Chen, M., Li, L. C., et al. (2012). Overexpression of soybean $G m C B L 1$ enhances abiotic stress tolerance and promotes hypocotyl elongation in Arabidopsis. Biochem. Biophys. Res. Commun. 427, 731-736. doi: 10.1016/j.bbrc.2012.09.128

Liu, J., and Zhu, J.-K. (1998). A calcium sensor homolog required for plant salt tolerance. Science 280, 1943-1945.

Livak, K. J., and Schmittgen, T. D. (2001). Analysis of relative gene expression data using real-time quantitative PCR and the $2^{-\Delta \Delta C T}$ method. Methods 25, 402-408. doi: 10.1006/meth.2001.1262

Long, N. V., Dolstra, O., Malosetti, M., Kilian, B., Graner, A., Visser, R. G. F., et al. (2013). Association mapping of salt tolerance in barley (Hordeum vulgare L.). Theor. Appl. Genet. 126, 2335-2351. doi: 10.1007/s00122-013-2139-0

Mähs, A., Steinhorst, L., Han, J. P., Shen, L. K., Wang, Y., and Kudla, J. (2013). The calcineurin B-like $\mathrm{Ca}^{2+}$ sensors $C B L 1$ and $C B L 9$ function in pollen germination and pollen tube growth in Arabidopsis. Mol. Plant 6, 1149-1162. doi: $10.1093 / \mathrm{mp} / \mathrm{sst} 095$

Martínez-Atienza, J., Jiang, X., Garciadeblas, B., Mendoza, I., Zhu, J.-K., Pardo, J. M., et al. (2007). Conservation of the salt overly sensitive pathway in rice. Plant Physiol. 143, 1001-1012. doi: 10.1104/pp.106.092635

Mekawy, A. M., Assaha, D. V., Yahagi, H., Tada, Y., Ueda, A., and Saneoka, H. (2015). Growth, physiological adaptation, and gene expression analysis of two Egyptian rice cultivars under salt stress. Plant Physiol. Biochem. 87, 17-25. doi: 10.1016/j.plaphy.2014.12.007

Munns, R., and Tester, M. (2008). Mechanisms of salinity tolerance. Annu. Rev. Plant Biol. 59, 651-681. doi: 10.1146/annurev.arplant.59.032607.092911

Oh, S. J., Kwon, C. W., Choi, D. W., Song, S. I., and Kim, J. K. (2007). Expression of barley HvCBF4 enhances tolerance to abiotic stress in transgenic rice. Plant Biotechnol. J. 5, 646-656. doi: 10.1111/j.1467-7652.2007.00272.x

Ozawa, K. (2012). “A high-efficiency Agrobacterium-mediated transformation system of rice (Oryza sativa L.)," in Transgenic Plants: Methods and Protocols, eds J. M. Dunwell and A. C. Wetten (Totowa, NJ: Humana Press), 51-57.

Pandey, G. K., Cheong, Y. H., Kim, K.-N., Grant, J. J., Li, L., Hung, W., et al. (2004). The calcium sensor calcineurin B-like 9 modulates abscisic acid sensitivity and biosynthesis in Arabidopsis. Plant Cell 16, 1912-1924. doi: 10.1105/tpc.021311

Pandey, G. K., Grant, J. J., Cheong, Y. H., Kim, B.-G., and Luan, S. (2008). Calcineurin-B-like protein CBL9 interacts with target kinase CIPK3 in the regulation of ABA response in seed germination. Mol. Plant 1, 238-248. doi: $10.1093 / \mathrm{mp} / \mathrm{ssn} 003$ 
Qiu, Q.-S., Guo, Y., Dietrich, M. A., Schumaker, K. S., and Zhu, J.-K. (2002). Regulation of SOS1, a plasma membrane $\mathrm{Na}^{+} / \mathrm{H}^{+}$exchanger in Arabidopsis thaliana, by SOS2 and SOS3. Proc. Natl. Acad. Sci. U.S.A. 99, 8436-8441. doi: 10.1073/pnas.122224699

Quan, R., Lin, H., Mendoza, I., Zhang, Y., Cao, W., Yang, Y., et al. (2007). $S C A B P 8 / C B L 10$, a putative calcium sensor, interacts with the protein kinase SOS2 to protect Arabidopsis shoots from salt stress. Plant Cell 19, 1415-1431. doi: 10.1105/tpc.106.042291

Rao, X.-L., Zhang, X.-H., Li, R.-J., Shi, H.-T., and Lu, Y.-T. (2011). A calcium sensor-interacting protein kinase negatively regulates salt stress tolerance in rice (Oryza sativa). Funct. Plant Biol. 38, 441-450. doi: 10.1071/FP10205

Ren, X. L., Qi, G., Feng, H., Zhao, S., Zhao, S., Wang, Y., et al. (2013). Calcineurin B-like protein CBL10 directly interacts with $A K T 1$ and modulates $\mathrm{K}^{+}$homeostasis in Arabidopsis. Plant J. 74, 258-266. doi: 10.1111/tpj.12123

Rengasamy, P. (2002). Transient salinity and subsoil constraints to dryland farming in Australian sodic soils: an overview. Aust. J. Exp. Agric. 42, 351-361. doi: 10.1071/EA01111

Rivandi, J., Miyazaki, J., Hrmova, M., Pallotta, M., Tester, M., and Collins, N. C. (2011). A SOS3 homologue maps to HvNax4, a barley locus controlling an environmentally sensitive $\mathrm{Na}^{+}$exclusion trait. J. Exp. Bot. 62, 1201-1216. doi: $10.1093 /$ jxb/erq346

Romeza, J., and Flowers, T. (2008). Ecology. Crops for a salinized world. Science 322, 1478-1480. doi: 10.1126/science. 1168572

Sánchez-Barrena, M. J., Fujii, H., Angulo, I., Martinez-Ripoll, M., Zhu, J. K., and Albert, A. (2007). The structure of the C-terminal domain of the protein kinase AtSOS2 bound to the calcium sensor AtSOS3. Mol. Cell 26, 427-435. doi: 10.1016/j.molcel.2007.04.013

Shavrukov, Y. (2013). Salt stress or salt shock: which genes are we studying? J. Exp. Bot. 64, 119-127. doi: 10.1093/jxb/ers316

Tang, R.-J., Liu, H., Yang, Y., Yang, L., Gao, X.-S., Garcia, V. J., et al. (2012). Tonoplast calcium sensors $C B L 2$ and $C B L 3$ control plant growth and ion homeostasis through regulating V-ATPase activity in Arabidopsis. Cell Res. 22, 1650-1665. doi: 10.1038/cr.2012.161

Tang, R. J., Yang, Y., Yang, L., Liu, H., Wang, C. T., Yu, M. M., et al. (2014). Poplar calcineurin B-like proteins PtCBL10A and $P t C B L 10 B$ regulate shoot salt tolerance through interaction with PtSOS2 in the vacuolar membrane. Plant Cell Environ. 37, 573-588. doi: 10.1111/pce.12178

Thoday-Kennedy, E., Jacobs, A., and Roy, S. (2015). The role of the CBL-CIPK calcium signalling network in regulating ion transport in response to abiotic stress. Plant Growth Regul. 76, 3-12. doi: 10.1007/s10725-015-0034-1
Wang, Z., Chen, M., Chen, T., Xuan, L., Li, Z., Du, X., et al. (2014). TRANSPARENT TESTA2 regulates embryonic fatty acid biosynthesis by targeting FUSCA3 during the early developmental stage of Arabidopsis seeds. Plant J. 77, 757-769. doi: $10.1111 /$ tpj.12426

Weinl, S., and Kudla, J. (2009). The CBL-CIPK $\mathrm{Ca}^{2+}$-decoding signaling network: function and perspectives. New Phytol. 184, 517-528. doi: 10.1111/j.14698137.2009.02938.x

Wu, D., Shen, Q., Cai, S., Chen, Z.-H., Dai, F., and Zhang, G. (2013). Ionomic responses and correlations between elements and metabolites under salt stress in wild and cultivated barley. Plant Cell Physiol. 54, 1976-1988. doi: $10.1093 / \mathrm{pcp} / \mathrm{pct} 134$

Xiang, Y., Huang, Y., and Xiong, L. (2007). Characterization of stress-responsive CIPK genes in rice for stress tolerance improvement. Plant Physiol. 144, 1416-1428. doi: 10.1104/pp.107.101295

Xu, J., Li, H.-D., Chen, L.-Q., Wang, Y., Liu, L.-L., He, L., et al. (2006). A protein kinase, interacting with two calcineurin B-like proteins, regulates $\mathrm{K}^{+}$transporter AKT1 in Arabidopsis. Cell 125, 1347-1360. doi: 10.1016/j.cell.2006.06.011

Zhang, H., Yang, B., Liu, W.-Z., Li, H., Wang, L., Wang, B., et al. (2014). Identification and characterization of $C B L$ and $C I P K$ gene families in canola (Brassica napus L.). BMC Plant Biol. 14:8. doi: 10.1186/1471-2229-14-8

Zhang, H., Yin, W., and Xia, X. (2008). Calcineurin B-Like family in Populus: comparative genome analysis and expression pattern under cold, drought and salt stress treatment. Plant Growth Regul. 56, 129-140. doi: 10.1007/s10725008-9293-4

Zhou, L., Lan, W., Chen, B., Fang, W., and Luan, S. (2015). A calcium sensorregulated protein kinase, CALCINEURIN B-LIKE PROTEIN-INTERACTING PROTEIN KINASE19, is required for pollen tube growth and polarity. Plant Physiol. 167, 1351-1360. doi: 10.1104/pp.114.256065

Conflict of Interest Statement: The authors declare that the research was conducted in the absence of any commercial or financial relationships that could be construed as a potential conflict of interest.

Copyright (c) 2016 Guo, Chen, Hussain, Zhang and Jiang. This is an open-access article distributed under the terms of the Creative Commons Attribution License (CC $B Y)$. The use, distribution or reproduction in other forums is permitted, provided the original author(s) or licensor are credited and that the original publication in this journal is cited, in accordance with accepted academic practice. No use, distribution or reproduction is permitted which does not comply with these terms. 